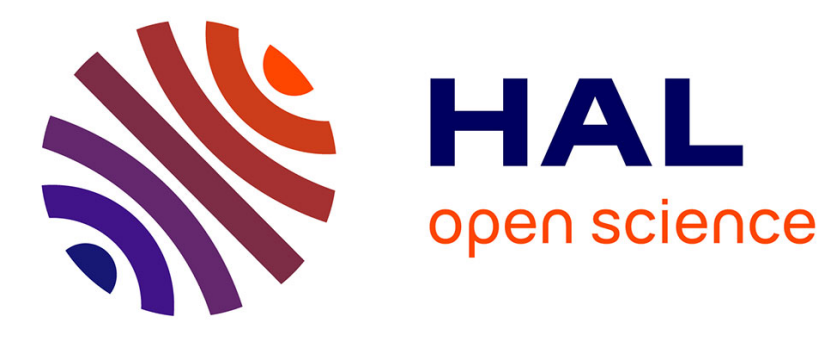

\title{
Structure and Dynamics of High-Temperature Strontium Aluminosilicate Melts
}

Pierre Florian, Alexey Novikov, James Drewitt, Louis Hennet, Vincent Sarou-Kanian, Dominique Massiot, Henry Fischer, Daniel R Neuville

\section{- To cite this version:}

Pierre Florian, Alexey Novikov, James Drewitt, Louis Hennet, Vincent Sarou-Kanian, et al.. Structure and Dynamics of High-Temperature Strontium Aluminosilicate Melts. Physical Chemistry Chemical Physics, 2018, 20, pp.27865-27877. 10.1039/C8CP04908D . hal-01898249

\author{
HAL Id: hal-01898249 \\ https://hal.science/hal-01898249
}

Submitted on 5 Dec 2020

HAL is a multi-disciplinary open access archive for the deposit and dissemination of scientific research documents, whether they are published or not. The documents may come from teaching and research institutions in France or abroad, or from public or private research centers.
L'archive ouverte pluridisciplinaire HAL, est destinée au dépôt et à la diffusion de documents scientifiques de niveau recherche, publiés ou non, émanant des établissements d'enseignement et de recherche français ou étrangers, des laboratoires publics ou privés. 
Florian, P., Novikov, A., Drewitt, J., Hennet, L., Sarou-Kanian, V., Massiot, D., Fischer, H. E., \& Neuville, D. R. (2018). Structure and Dynamics of High-Temperature Strontium Aluminosilicate Melts. Physical Chemistry Chemical Physics, 20(44), 27865-27877. https://doi.org/10.1039/C8CP04908D

Peer reviewed version

Link to published version (if available):

10.1039/C8CP04908D

Link to publication record in Explore Bristol Research

PDF-document

This is the author accepted manuscript (AAM). The final published version (version of record) is available online via RSC at https://pubs.rsc.org/en/Content/ArticleLanding/2018/CP/C8CP04908D\#!divAbstract . Please refer to any applicable terms of use of the publisher.

\section{University of Bristol - Explore Bristol Research}

General rights

This document is made available in accordance with publisher policies. Please cite only the published version using the reference above. Full terms of use are available:

http://www.bristol.ac.uk/pure/user-guides/explore-bristol-research/ebr-terms/ 


\section{Structure and Dynamics of High-Temperature Strontium Aluminosilicate Melts}

Pierre Florian ${ }^{1, *}$, Alexey Novikov ${ }^{1,2}$, James W. E. Drewitt ${ }^{3}$, Louis Hennet ${ }^{1}$, Vincent SarouKanian $^{1}$, Dominique Massiot ${ }^{1}$, Henry E. Fischer ${ }^{3}$ and Daniel R. Neuville ${ }^{2}$

${ }^{1}$ CNRS, CEMHTI UPR3079, Université d'Orléans, F-45071 Orléans, France

2 IPGP UMR7154 CNRS, Géomatériaux, Paris Sorbonne Cité, 75005 Paris, France

${ }^{3}$ School of Earth Sciences, University of Bristol, Bristol, BS8 1RJ, UK

${ }^{4}$ Institut Laue-Langevin, 71 avenue des Martyrs, CS 20156, 38042 Grenoble cedex 9, France

High temperature, Melt, NMR, Neutron diffraction. 


\section{Abstract}

We report the study of high-temperature melts $\left(1600^{\circ} \mathrm{C}-2300^{\circ} \mathrm{C}\right)$ and related glasses in the SrO$\mathrm{Al}_{2} \mathrm{O}_{3}-\mathrm{SiO}_{2}$ phase diagram considering three series: (i) depolymerized ([SrO]/[ $\left.\mathrm{Al}_{2} \mathrm{O}_{3}\right]=3$ ); (ii) fully polymerized $\left([\mathrm{SrO}] /\left[\mathrm{Al}_{2} \mathrm{O}_{3}\right]=1\right)$; and (iii) per-aluminous $\left([\mathrm{SrO}] /\left[\mathrm{Al}_{2} \mathrm{O}_{3}\right]<1\right)$. By considering results from high-temperature ${ }^{27} \mathrm{Al} \mathrm{NMR}$ and high temperature neutron diffraction, we demonstrate that the structure of the polymerized melts is controlled by a close-to-random distribution of $\mathrm{Al}$ and $\mathrm{Si}$ in the tetrahedral sites, while the depolymerized melts show smaller rings with a possible loss of Non-Bridging Oxygens on $\mathrm{AlO}_{4}$ units during cooling for high-silica compositions. Few five-fold coordinated ${ }^{\mathrm{V}} \mathrm{Al}$ sites are present in all compositions except peraluminous ones where high amounts of high-coordinated aluminium are found in the glasses and melts with complex temperature dependence. In the high-temperature melts, Strontium has a coordination number of 8 or lower, i.e. lower than in the corresponding glasses.

The dynamics of the high-temperature melt were studied from ${ }^{27} \mathrm{Al}$ NMR relaxation and compared to macroscopic shear viscosity data. These methods provide correlation times in close agreement. At very high temperatures, the NMR correlation times can be related to oxygen selfdiffusion coefficient and we show a decrease of the latter with increasing $\mathrm{Si} /(\mathrm{Al}+\mathrm{Si})$ ratio for polymerized melts with no compositional dependence for depolymerized ones. The dominant parameter controlling the temperature dependence of the aluminum environment of all melts is the distribution of $\mathrm{Al}-(\mathrm{OSi})_{\mathrm{p}}(\mathrm{OAl})_{(4-\mathrm{p})}$ units. 


\section{Introduction}

Aluminosilicates glass compositions are of widespread use in material science where they have found numerous industrial applications as e.g. cover glass for high-end display devices, holographic optical elements, high strength material with moderate expansion for radomes and zero expansion glass-ceramics. They are also central to Earth Sciences as melt models of magmas. Our understanding of the atomic-scale structure of these materials in their glassy form has advanced substantially over the last decades owing to improvements in experimental methods (Greaves and Sen, 2007), and the interaction between alkaline, alkaline-earth or rare-earth cations and the aluminosilicate network is now grounded on solid rules (Stebbins et al., 2013). Those materials possess basic $\mathrm{TO}_{4}$ building blocks with $\mathrm{T}=\mathrm{Si}$ or $\mathrm{Al}$ held together by covalent bonds when sharing corner(s) or electrostatic forces between Non-Bridging Oxygens (NBO) and counter cation(s) such as alkali or alkaline-earth elements. To understand and relate atomic arrangements to physical properties, some peculiar species have been outlined such as five-coordinated aluminum VAl (McMillan and Kirkpatrick, 1992; Neuville et al., 2006; Neuville et al., 2008b), non-stoichiometric NBO (Stebbins and Xu, 1997), NBO on aluminum species (Jaworski et al., 2015) or the putative tricluster oxygen which connects three tetrahedral species (Lacy, 1963; Toplis et al., 1997) all of those building blocks possibly organizing themselves at a larger scale into percolation channels (Le Losq et al., 2017). This picture, developed to describe glasses is used to provide a "snapshot" view of melt structure at high temperature (Stebbins, 2016). Nevertheless industrial high-temperature melt phase processes, like petrologic and geodynamic processes, cannot be understood without addressing their dynamics.

Aluminosilicate melt's diffusivity, viscosity, electrical and thermal conductivity have receive much experimental and computational attention ( $\mathrm{Ni}$ et al., 2015), yet only a few in-situ spectroscopic characterizations have been performed due to challengingly high melting temperatures (Neuville et al., 2014). For pure aluminosilicate melt compositions, available X-ray scattering (Krishnan et al., 2000) and Nuclear Magnetic Resonance (NMR) (Poe et al., 1992) results reveal a short-range structure of the high-temperature liquid similar to that of the corresponding glasses, containing a significant proportion of ${ }^{\mathrm{V}} \mathrm{Al}$ species and a viscosity microscopic mechanism driven by the atomic-scale fluctuations around aluminum at high alumina contents. 
In the case of alkali aluminosilicates, sodium-based compositions are the most extensively studied in-situ at high temperature. Inelastic neutron scattering (Kargl and Meyer, 2004) and ${ }^{23} \mathrm{Na}$ NMR spectroscopy (George and Stebbins, 1996; Le Losq et al., 2014; Liu et al., 1987; Maekawa et al., 1997; Stebbins et al., 1985) showed rapid sodium mobility above $300^{\circ} \mathrm{C}$, mostly responsible for the relaxation and the conductivity. When $\mathrm{Al} / \mathrm{Na}>1$ sodium charge-compensating $\mathrm{A}_{1} \mathrm{O}_{4}{ }^{-}$units become dominant and the barrier against individual hops increases leading to a decrease in sodium mobility. The aluminosilicate network has been found by Raman spectroscopy (Neuville and Mysen, 1996) to be formed by an $\mathrm{Al} / \mathrm{Si}$ distribution on the corner-shared $\mathrm{TO}_{4}$ sites forming a fully polymerized three-dimensional network. In this case Si observed by ${ }^{29} \mathrm{Si}$ NMR (Liu et al., 1987) as been seen to be rather immobile below the glass transition temperature. High-field ${ }^{27} \mathrm{Al}$ NMR data show also a clear increase of the ${ }^{\mathrm{V}} \mathrm{Al}$ concentration (denoted hereafter as $\left[{ }^{\mathrm{V}} \mathrm{Al}\right]$ ) with increasing temperature in the per-aluminous melts, whereas it is much more stable in the peralkaline ones (Le Losq et al., 2014).

In the case of alkaline-earth aluminosilicates the investigations concentrated mostly on calciumbased compositions (CAS). X-ray absorption spectroscopy (Neuville et al., 2008a) demonstrated an increase of $\left[{ }^{\mathrm{V}} \mathrm{Al}\right]$ with temperature in the fully polymerized composition (anorthite), later confirmed by neutron diffraction (Jakse et al., 2012) which showed the presence of significant amounts of $\mathrm{AlO}_{5}$ units, oxygen triclusters and $\mathrm{NBO}$, even in fully charge-compensated composition. ${ }^{27} \mathrm{Al}$ NMR (Gruener et al., 2001; Kanehashi and Stebbins, 2007) has given some insight on the dynamics taking place in calcium aluminosilicates, showing that NMR, viscosity and conductivity relaxation times coincide in the high-temperature regime whereas a decoupling occurs near the glass transition temperature due to the $\mathrm{Ca}$ motion. A similar result was obtained on magnesium aluminosilicate compositions (George and Stebbins, 1998) with the diffusion of $\mathrm{Mg}$ shown to be strongly coupled to the network motion at temperatures above the glass transition temperature $\mathrm{T}_{\mathrm{g}}$. Higher concentrations of $\mathrm{NBOs}$ and of $\mathrm{AlO}_{5}$ species with increasing temperature were inferred by comparing quench-rate dependent and in-situ ${ }^{27} \mathrm{Al}$ NMR studies (Stebbins et al., 2008). Molecular Dynamic Simulations (Benoit et al., 2001) have also observed the excess of NBOs in the melt, along with the violation of the aluminum avoidance principle and the presence of "defects" such as five-fold coordinated silicon. Moreover, MD simulation using the isoconfigurational ensemble method suggested the presence in the melts of dynamical 
heterogeneities related to concentration fluctuations between Si-rich and (Ca,Al)-rich regions (Vargheese et al., 2010).

All of the puzzle's pieces (NBO, high-coordinated Al, tri-bonded oxygens, cation mobility...) seem to be more or less accepted but the way they interact, or not, with each other is still an open question. Of particular importance is the dynamics of the aluminosilicate network in the melt at superliquidus and supercooled temperatures, and much remains to be done experimentally in this field. We hence used high-temperature ${ }^{27} \mathrm{Al}$ NMR and neutron diffraction techniques to explore alkaline-earth aluminosilicate compositions with various degrees of polymerization. Following our previous investigation (Novikov et al., 2017) we chose strontium aluminosilicate compositions for which we already assessed structure and macroscopic properties of the glasses. Three different compositional regions were explored: along the "tectosilicate" or "charge balanced" join $R=$ $[\mathrm{SrO}] /\left[\mathrm{Al}_{2} \mathrm{O}_{3}\right]=1$, in the per-alkaline field with compositions on the join $R=3$, and in the peraluminous $R<1$ domain. If compositions along the join $R=1$ are expected to be fully polymerized with only a small amount of ${ }^{\mathrm{V}} \mathrm{Al}$ (we found $\left[{ }^{\mathrm{V}} \mathrm{Al}\right]<4 \%$ in the glasses) and NBOs, compositions along the join $R=3$ do contain a significant proportion of NBOs for charge balance reasons. Besides, an important population of $\mathrm{AlO}_{5}$ and even $\mathrm{AlO}_{6}$ is expected in the $\mathrm{R}<1$ field. Such marked changes are bound to impact the melt' structure and dynamics and, to the best of our knowledge, have not yet been explored in such a systematic way in-situ.

\section{Experimental}




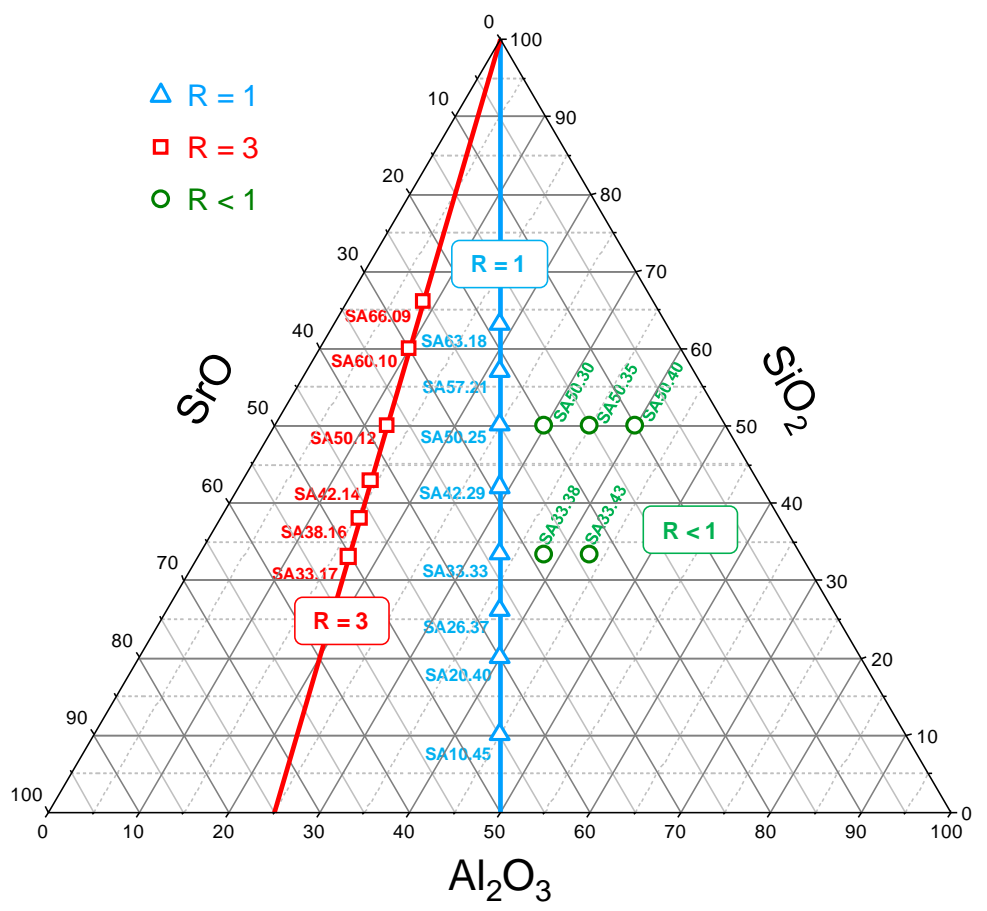

Figure 1: ternary diagram showing all investigated compositions. Per-alkaline compositions are represented as red squares, compensated ones as blue triangles and per-aluminous ones as green circles.

All samples were taken from the batches studied previously (Charpentier et al., 2018; Novikov et al., 2017). Droplets of glasses suitable for the NMR levitation experiments were obtained using an "external" levitation device. Sample compositions (figure 1) are named according to their $\mathrm{SiO}_{2}$ and $\mathrm{Al}_{2} \mathrm{O}_{3}$ molar composition: $\mathrm{SASiO}_{2} \% \cdot \mathrm{Al}_{2} \mathrm{O}_{3} \%$, the molar fraction of $\mathrm{SrO}$ being $\left(100-\mathrm{SiO}_{2} \%\right.$ $\left.\mathrm{Al}_{2} \mathrm{O}_{3} \%\right)$. 


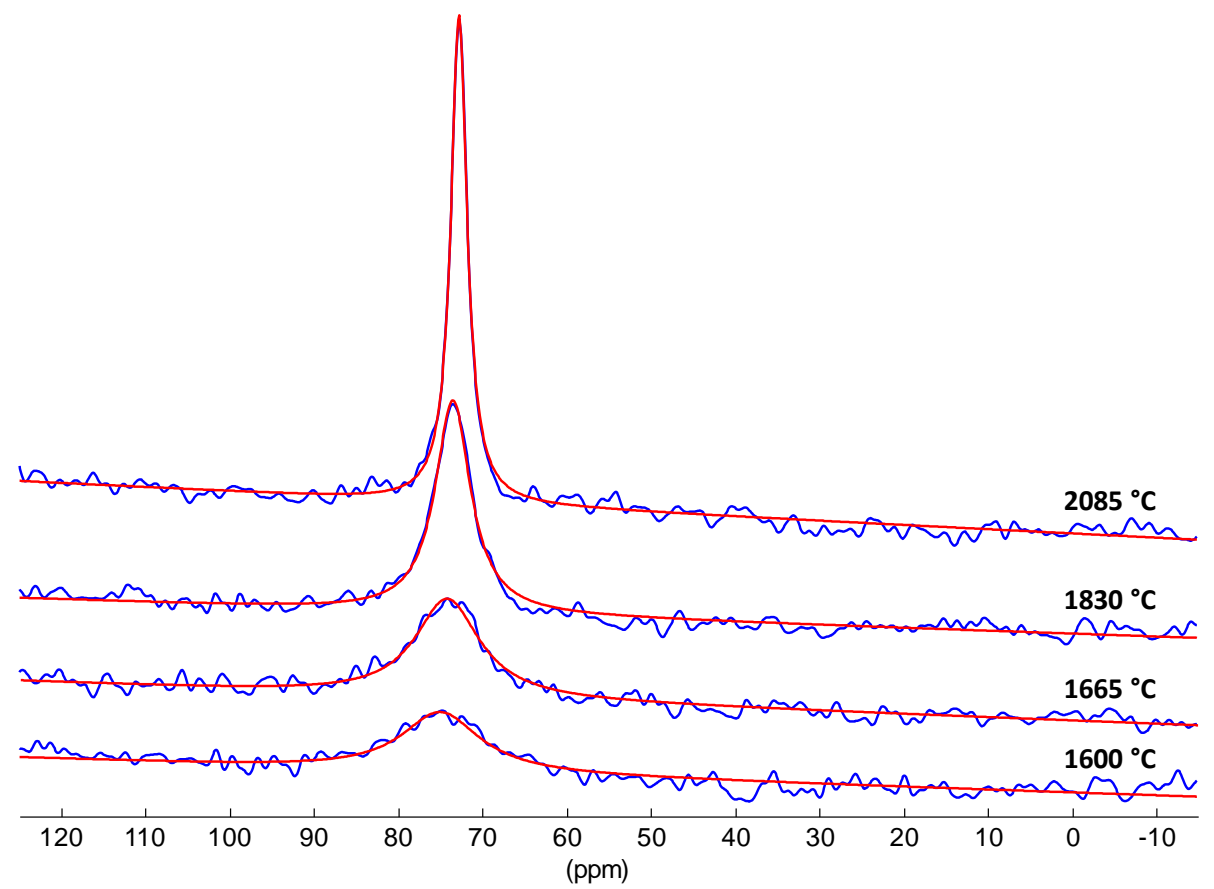

Figure 2. One-scan High-Temperature ${ }^{27} \mathrm{Al}$ NMR spectra (blue lines) of SA10.45 melt at different temperatures during the melt's cooling. The red lines are fits of the NMR signal with Lorentzian function.

The very high-temperature NMR experiments were performed on a 9.4 T Bruker Avance I spectrometer operating at $104.3 \mathrm{MHz} .{ }^{27} \mathrm{Al}$ chemical shift are referenced to $1 \mathrm{M}$ solution of $\mathrm{Al}\left(\mathrm{NO}_{3}\right)_{3}$. The setup is based on an aerodynamic levitation device located inside the NMR probe. The sample (a sphere of $2.6 \mathrm{~mm} \pm 0.5 \mathrm{~mm}$ diameter) is in aerodynamically levitated on a gas stream (air) and heated and heated at top and bottom by two $\mathrm{CO}_{2}$ lasers as previously described (Florian et al., 1995). The sample is heated and stabilized (a few seconds) above its melting point and the ${ }^{27} \mathrm{Al}$ NMR signal is recorded every $10 \mathrm{~ms}$ during the free cooling of the sample when the laser is turned off. The temperature of the sample during the experiments was monitored with an IMPAC IN $140 / 5-\mathrm{H}$ pyrometer $(\lambda=5.14 \mu \mathrm{m})$ allowing measurements from 500 to $2500{ }^{\circ} \mathrm{C}$. However, the area monitored by the pyrometer was greater than the sample' size. A temperature calibration was made against the observed recalescence of compounds with known crystallization temperature $\left(\mathrm{Al}_{2} \mathrm{O}_{3}, \mathrm{SrSiO}_{3}, \mathrm{CaMgSi}_{2} \mathrm{O}_{6}, \mathrm{Li}_{2} \mathrm{SiO}_{3}\right)$. Spheres of different diameters were used for each compound and several crystallization events were registered and averaged for each sphere. Therefore, all presented temperatures are reliable within $\pm 50{ }^{\circ} \mathrm{C}$. Typical spectra obtained this way are shown in Figure 2.

The relaxation time of ${ }^{27} \mathrm{Al}$ have been measured at high temperature for two compositions: $\mathrm{SA33.17:} \mathrm{T}_{1} \sim 400 \mu \mathrm{s} \pm 50 \mu \mathrm{s}, \mathrm{T}_{2} \sim 350 \mu \mathrm{s} \pm 50 \mu \mathrm{s}, 1 / \pi \Delta v_{1 / 2} \sim 370 \mu \mathrm{s} \pm 20 \mu \mathrm{s}$ and $\mathrm{SA} 33.38: \mathrm{T}_{1} \sim$ 
$880 \mu \mathrm{s} \pm 30 \mu \mathrm{s}, \mathrm{T}_{2} \sim 800 \mu \mathrm{s} \pm 30 \mu \mathrm{s}, 1 / \pi \Delta \nu_{1 / 2} \sim 740 \mu \mathrm{s} \pm 20 \mu \mathrm{s}$, with $\mathrm{T}_{1}$ the spin-lattice relaxation time, $\mathrm{T}_{2}$ spin-spin relaxation time, and $\Delta v_{1 / 2}$ the full width at half maximum. These relaxation times are short enough to allow repetition of acquisition down to $10 \mathrm{~ms}\left(>5\right.$ times $\left.\mathrm{T}_{1}\right)$ and thus to obtain a time resolved signature of the melt during its cooling. This also minimizes the experimental time, reducing possible vaporization that has been checked to be negligible by measuring weight loss after the high-temperature experiment. The drawback of this procedure is that it does not allow signal averaging, limiting the sensitivity of the experiment and the increasingly broadened signal is progressively lost with increasing linewidth upon cooling. This is particularly true for the compositions containing the lowest amount of $\mathrm{Al}_{2} \mathrm{O}_{3}$.

The evolution of the NMR parameters with temperature and compositions have been fitted to adequate functions (detailed below) using the "NonLinearModelFit" build-in function of Mathematica 10.1 (Wolfram Research, 2015) including statistical analysis.

High-temperature neutron diffraction (ND) measurements have been carried out on 5 samples (Hennet et al., 2014) using the aerodynamic levitation and laser heating system installed on the D4C diffractometer (Fischer et al., 2002) at the Institut Laue-Langevin in Grenoble (France), as described in (Hennet et al., 2006). Diffraction measurements were taken for the molten samples at temperatures above the melting point for all studied compositions, for the empty levitation device inside the diffraction chamber, and for vanadium samples for making an absolute normalization of the scattered intensity. The neutron wavelength used during the experiment was $0.4985 \AA$, giving a scattering vector Q-range of about $0.3-23.6 \AA^{-1}$. The data processing was performed using the program CORRECT (Howe et al., 1996), which corrects the data for attenuation, background, multiple scattering and inelasticity effects. The derived structure factors for all the measured samples are presented in figure 3 . 


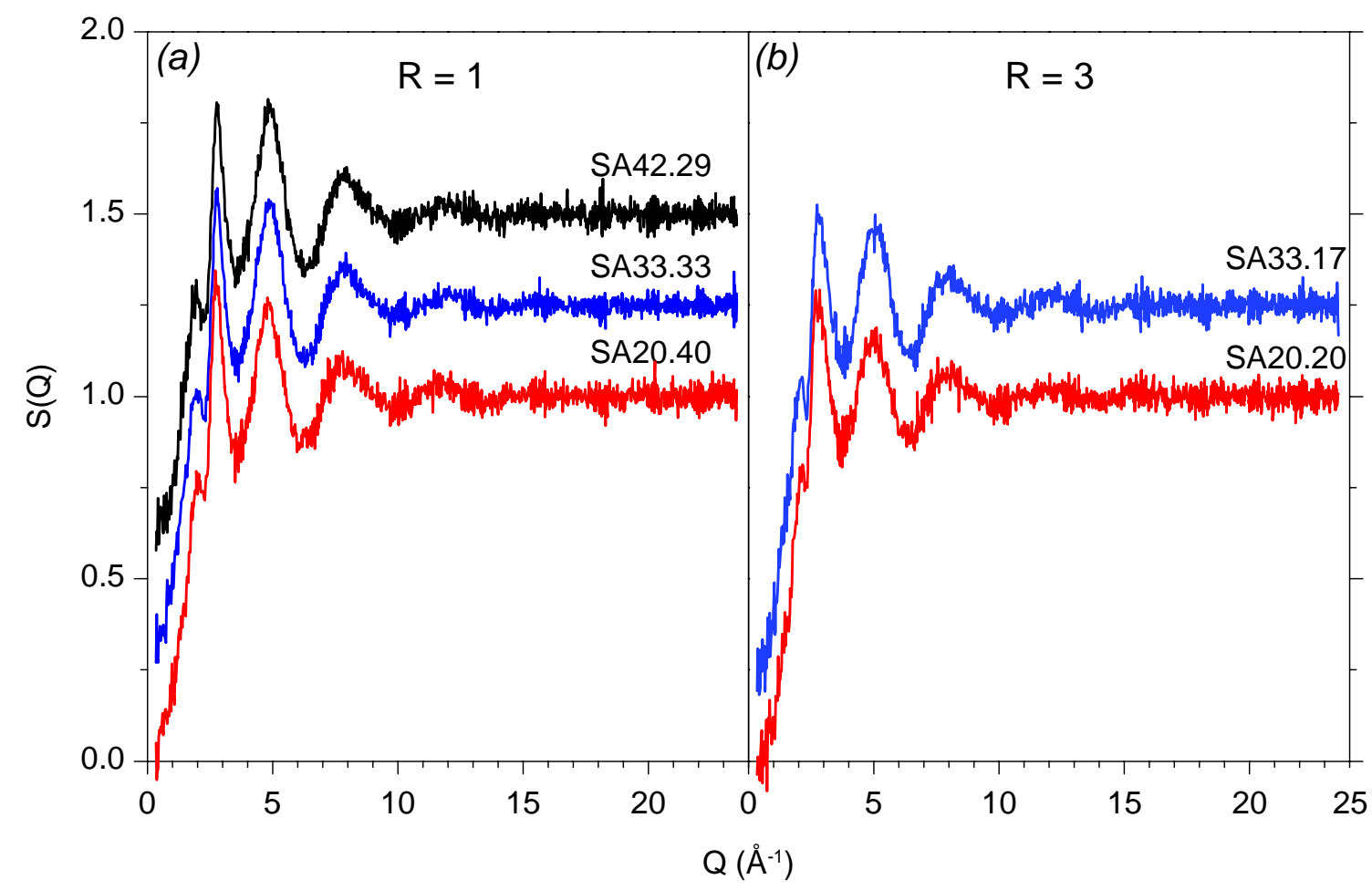

Figure 3. Total structure factors $S(Q)$ of the liquid SAS samples for $R=1$ (a) and 3 (b).

\section{Results}

\section{$N M R$}

The evolutions of the ${ }^{27} \mathrm{Al}$ chemical shift (line's position) as a function of temperature are given in figure 4 , for the full temperature range of this study. For both $R=1$ and $R=3$, the ${ }^{27} \mathrm{Al}$ chemical shift increases with decreasing silica molar ratio . In the per-aluminous region, substituting SrO by $\mathrm{Al}_{2} \mathrm{O}_{3}$ at fixed $\mathrm{SiO}_{2}$ content decreases significantly the ${ }^{27} \mathrm{Al}$ chemical shift (figure $4 \mathrm{c}$ ). As seen in figure 4 there is a linear evolution of the chemical shift with respect to temperature in this very superliquidus regime $\left(T>2 \times T_{g}\right)$, in agreement with our previous observations on alkaline-earth aluminate (Capron et al., 2001) and rare-earth aluminosilicate (Florian et al., 2007) compositions. Significant scattering is observed when the signal broadens at low temperature or at low $\mathrm{Al}_{2} \mathrm{O}_{3}$ content due to diminishing signal to noise ratio as described above. For each cooling experiment the evolution of the ${ }^{27} \mathrm{Al}$ chemical shift versus temperature has been fitted with a linear function, where the slopes and intercepts are given in table 1. 
(a)

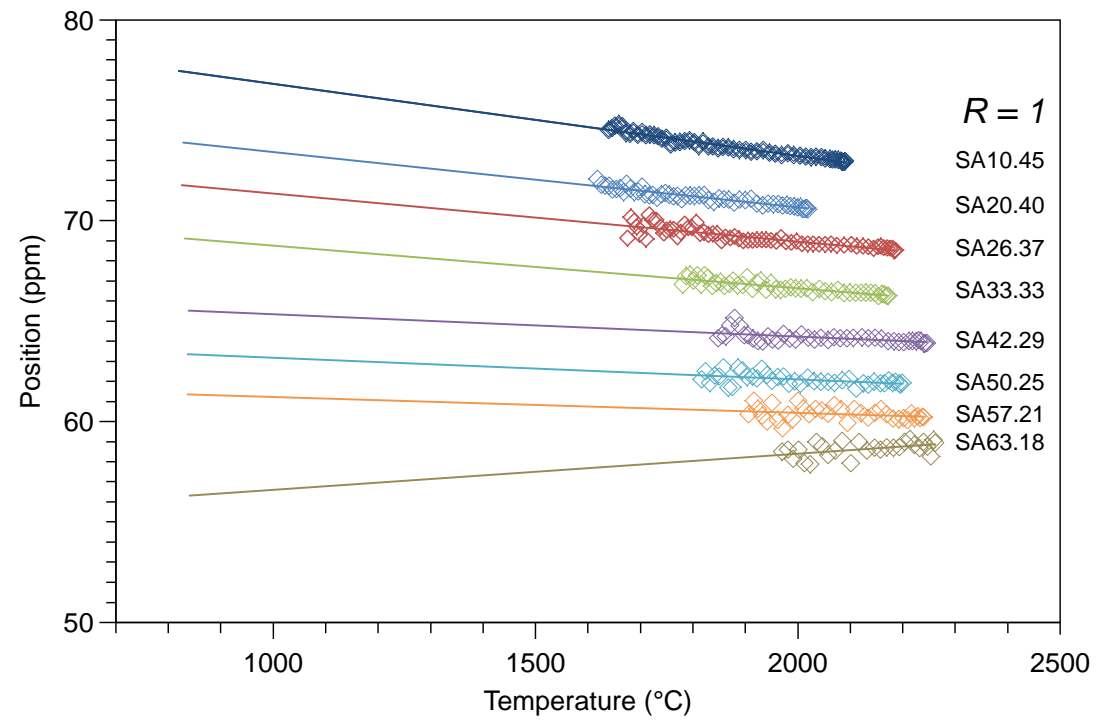

(b)

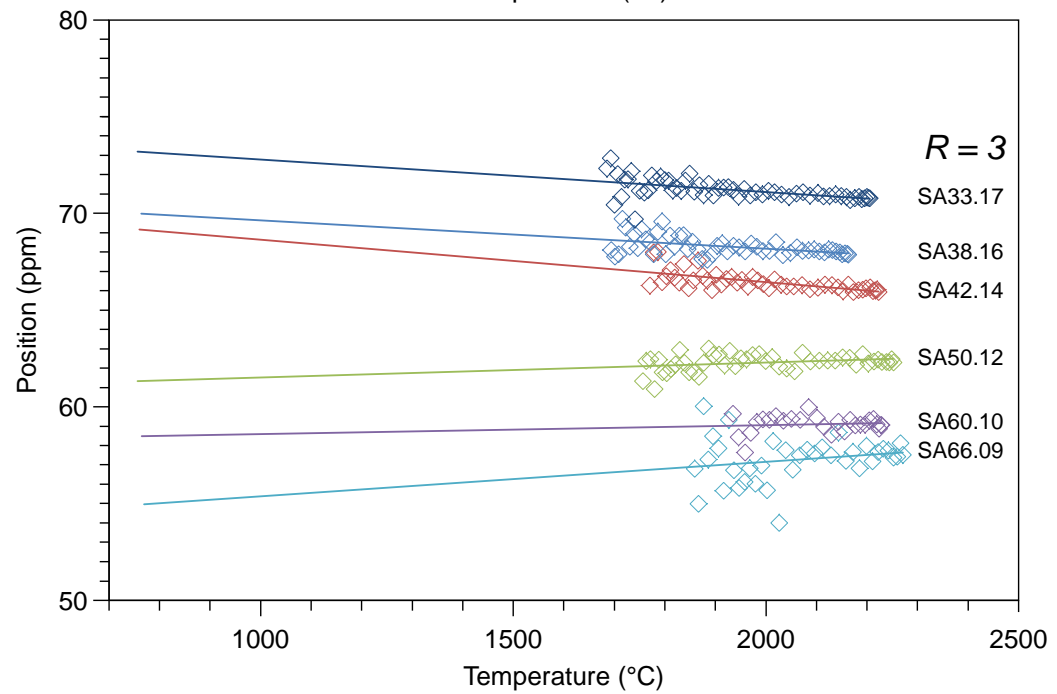

(c)

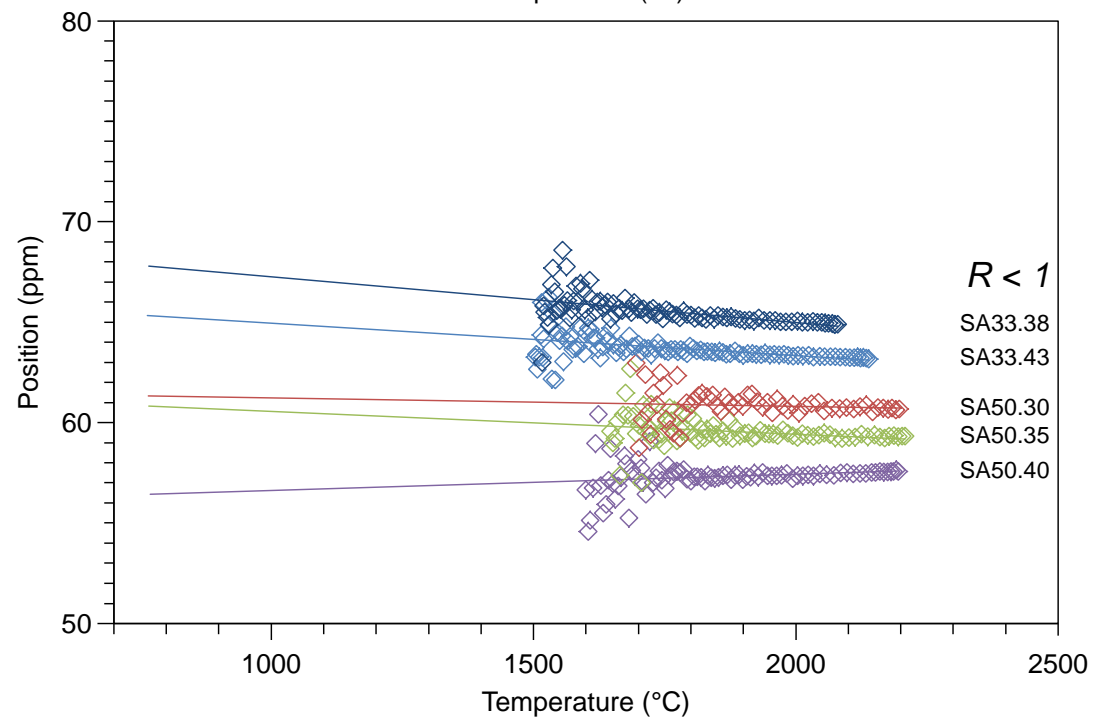

Figure 4. Evolution of the ${ }^{27} \mathrm{Al}$ NMR line's position during free cooling of all compositions studied: (a) on the chargecompensation line $(R=1)$, (b) in the per-alkaline field $(R=3)$ and (c) in the per-aluminous region $(R<1)$. 
Reports of the evolution of ${ }^{27} \mathrm{Al}$ chemical shifts with temperature in the high-temperature melts are scarce. The ${ }^{27} \mathrm{Al}$ peak maximum has been observed to decrease with increasing temperature (from $65.1 \mathrm{ppm}$ at $1300{ }^{\circ} \mathrm{C}$ to $63.3 \mathrm{ppm} \pm 1 \mathrm{ppm}$ at $1400^{\circ} \mathrm{C}$ ) for a per-calcic aluminosilicate melt (Kanehashi and Stebbins, 2007). Our previous study of sodium aluminosilicate glasses (Le Losq et al., 2014) have also shown a decrease of $\delta_{\text {iso }}$ with increasing temperature $(d \delta / d T=-3.0 \mathrm{ppm} / 1000$ ${ }^{\circ} \mathrm{C}$ ) up to $T_{m}$ where it drops, followed by a slower decrease thereafter with $d \delta / d T \sim-1.6 \mathrm{ppm} / 1000$ ${ }^{\circ} \mathrm{C}$, consistent with our current measurement found in the range -3.6 to $1.5 \mathrm{ppm} / 1000{ }^{\circ} \mathrm{C}$. This slope range fits also within the one observed for lanthanum and yttrium melts using a levitationtype experiment (Florian et al., 2007).

\begin{tabular}{l|c|c|c|c|c|c} 
Sample & $\begin{array}{c}<\delta_{\text {iso }}>\text { glass } \\
(\mathrm{ppm})\end{array}$ & $\begin{array}{c}\text { Slope } \\
\left(\mathrm{ppm} / 1000^{\circ} \mathrm{C}\right)\end{array}$ & $\begin{array}{c}\text { Intercept } \\
(\mathrm{ppm})\end{array}$ & $\begin{array}{c}\delta_{2000^{\circ} \mathrm{C}}\left(\mathrm{T}^{\circ} \mathrm{C}\right) \\
(\mathrm{ppm})\end{array}$ & $\begin{array}{c}\mathrm{E}_{\mathrm{a}} \\
(\mathrm{kJ} / \mathrm{mol})\end{array}$ & $\begin{array}{c}\tau_{0} \\
(\mathrm{ps})\end{array}$ \\
\hline SA75.12 & 59.7 & & & & & \\
SA63.18 & 62.0 & $1.00(0.89)$ & $56.6(1.82)$ & $58.6(2001)$ & $132.5(9.8)$ & $0.468(0.240)$ \\
SA57.21 & 63.4 & $-1.11(0.82)$ & $62.7(1.65)$ & $61.0(2000)$ & $127.8(5.9)$ & $0.171(0.336)$ \\
SA50.25 & 65.0 & $-0.68(0.67)$ & $63.4(1.32)$ & $61.9(2005)$ & $136.1(3.9)$ & $0.201(0.043)$ \\
SA42.29 & 67.0 & $-1.32(0.27)$ & $66.9(0.54)$ & $64.1(1997)$ & $137.4(3.3)$ & $0.206(0.036)$ \\
SA33.33 & 70.3 & $-2.85(0.27)$ & $72.4(0.52)$ & $66.6(1996)$ & $137.1(2.5)$ & $0.153(0.021)$ \\
SA26.37 & 73.4 & $-2.43(0.17)$ & $73.8(0.33)$ & $69.0(1998)$ & $141.1(1.6)$ & $0.109(0.010)$ \\
SA20.40 & 75.2 & $-2.76(0.13)$ & $76.2(0.23)$ & $70.7(1999)$ & $140.1(1.9)$ & $0.065(0.007)$ \\
SA10.45 & 77.3 & $-3.64(0.10)$ & $80.5(0.19)$ & $73.2(2004)$ & $137.4(1.7)$ & $0.077(0.008)$ \\
\hline SA75.06 & 59.3 & & & & & \\
SA66.09 & 60.7 & $0.10(1.28)$ & $57.2(2.57)$ & $55.7(2002)$ & $86.5(13.4)$ & $1.990(1.407)$ \\
SA60.10 & 62.1 & $-0.89(0.84)$ & $61.1(1.65)$ & $59.3(1994)$ & $94.7(9.2)$ & $1.782(0.897)$ \\
SA50.12 & 65.0 & $0.92(0.46)$ & $60.4(0.91)$ & $62.4(2000)$ & $98.2(5.7)$ & $1.238(0.382)$ \\
SA42.14 & 68.3 & $-3.13(0.65)$ & $73.1(1.23)$ & $66.3(1995)$ & $90.4(5.1)$ & $1.700(0.486)$ \\
SA38.16 & 70.5 & $-0.41(0.49)$ & $69.0(0.91)$ & $68.0(1994)$ & $106.0(4.1)$ & $0.761(0.177)$ \\
SA33.17 & 73.5 & $-0.87(0.68)$ & $72.8(1.27)$ & $71.2(2005)$ & $110.7(4.1)$ & $0.774(0.179)$ \\
\hline SA50.30 & 62.3 & $-0.42(0.66)$ & $61.6(1.22)$ & $60.5(2005)$ & $131.1(3.9)$ & $0.188(0.042)$ \\
SA50.35 & 59.1 & $-1.17(0.47)$ & $61.8(0.88)$ & $59.3(2003)$ & $141.5(3.1)$ & $0.147(0.026)$ \\
SA50.40 & 55.7 & $0.82(0.45)$ & $55.8(0.84)$ & $57.4(2003)$ & $137.2(2.1)$ & $0.161(0.019)$ \\
SA33.38 & 67.3 & $-2.09(0.35)$ & $69.4(0.65)$ & $65.1(2002)$ & $142.8(1.7)$ & $0.141(0.014)$ \\
SA33.43 & 64.7 & $-1.49(0.27)$ & $66.5(0.51)$ & $63.3(2004)$ & $139.7(1.3)$ & $0.155(0.012)$
\end{tabular}

Table 1. Results of the linear fit of the melt's ${ }^{27} \mathrm{Al}$ positions vs temperature, observed position at $2000^{\circ} \mathrm{C}$, activation energies and pre-exponential factor (standard errors in parenthesis) and average positions $<\delta_{\text {iso }}>$ glass obtained from the studies of the glasses (Novikov et al., 2017). High silica containing compositions SA75.12 and SA75.06 have too high vaporization tendency to perform high temperature experiments.

As discussed above the linewidth $\Delta v_{1 / 2}$ of the ${ }^{27} \mathrm{Al}$ spectra (ranging from 0.4 to more than $2.5 \mathrm{kHz}$ ) is a measure of the spin-spin or spin-lattice relaxation time and thus of the dynamics of the molten sample at the atomic level and depends upon composition and temperature (figure $\mathrm{S} 1$ ). For $R=1$ and $R<1$ we observe an increasing linewidth with increasing $\mathrm{SiO}_{2}$ content, in contrast with the $R=3$ join where all $\Delta v_{1 / 2}$ vs $T$ curves are superimposed with the noise. Always well- 
defined at high temperatures, the precision of this measurement diminishes at low temperature and/or low alumina content.

In all cases, $\Delta v_{1 / 2}$ can be related to the aluminum correlation times of movement through the following set of hypotheses. We first checked on a couple of samples not prawned to vaporization that the ${ }^{27} \mathrm{Al}$ NMR spin-lattice relaxation time $T_{l}$ is obtained from the line width (see experimental section) according to:

$$
T_{1}=\frac{1}{\pi \Delta v_{1 / 2}}
$$

which means that we have reached the fully averaged motional regime. The evolution of $\Delta v_{1 / 2}$ as a function of temperature is hence an evolution of NMR relaxation times, known to be caused by the time-fluctuation of the NMR interactions. Under the assumption that the dominant interaction in our case is the quadrupolar interaction, $T_{l}$ can in turn be expressed as a function of the correlation time of the fluctuation of the quadrupolar interaction $\tau_{c}$ and the time-averaged dynamic quadrupolar product $\tilde{C}_{Q \eta}=\tilde{C}_{Q} \sqrt{1+\tilde{\eta}_{Q}^{2} / 3}$ of the aluminum sites (Abragam, 1961; Petit and Korb, 1988) :

$$
\frac{1}{T_{1}}=\frac{3}{10} \pi^{2} \frac{2 I+3}{I^{2}(2 I-1)} \tilde{C}_{Q \eta}^{2} \tau_{C}
$$

where $I$ is the nuclear spin $\left(5 / 2\right.$ for $\left.{ }^{27} \mathrm{Al}\right)$ and $\tilde{C}_{Q}$ and $\tilde{\eta}_{Q}$ are the time-averaged quadrupolar parameters. Equation (2) is valid as long as the auto-correlation function of the quadrupolar interaction's fluctuation $G$ is exponential: $G(\tau) \propto e^{-\tau / \tau_{c}}$ or in other words that the motion is Brownian. The time-average $\tilde{C}_{Q}$ can be statistically approximated by the spatially-averaged $\bar{C}_{Q}$ (ergodic approximation believed to be valid above $T_{g}$ ) measured in the glass using the GIM model (Le Caer and Brand, 1998), and $\tilde{\eta}_{Q}$ set to most probable value of 0.6 as used by this model, allowing us to compute $\tau_{c}$ from the measured $\Delta v_{l / 2}$ through equation (3):

$$
\tau_{c}=\frac{250}{24 \pi} \frac{\Delta v_{1 / 2}}{\tilde{C}_{Q \eta}^{2}}
$$


(a)

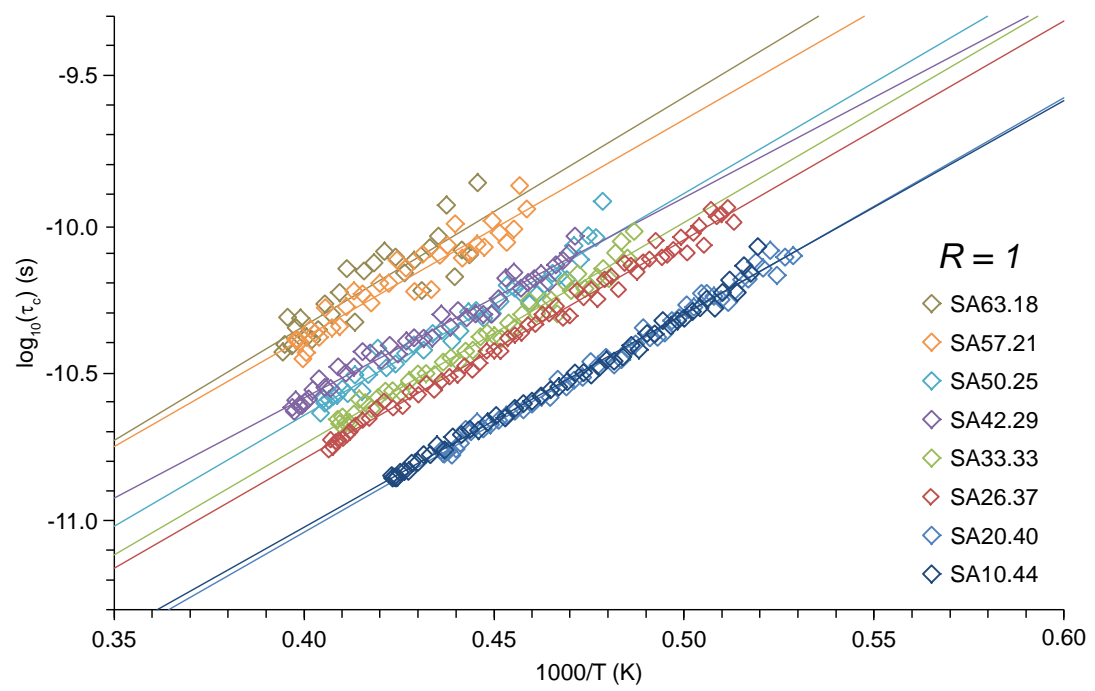

(b)

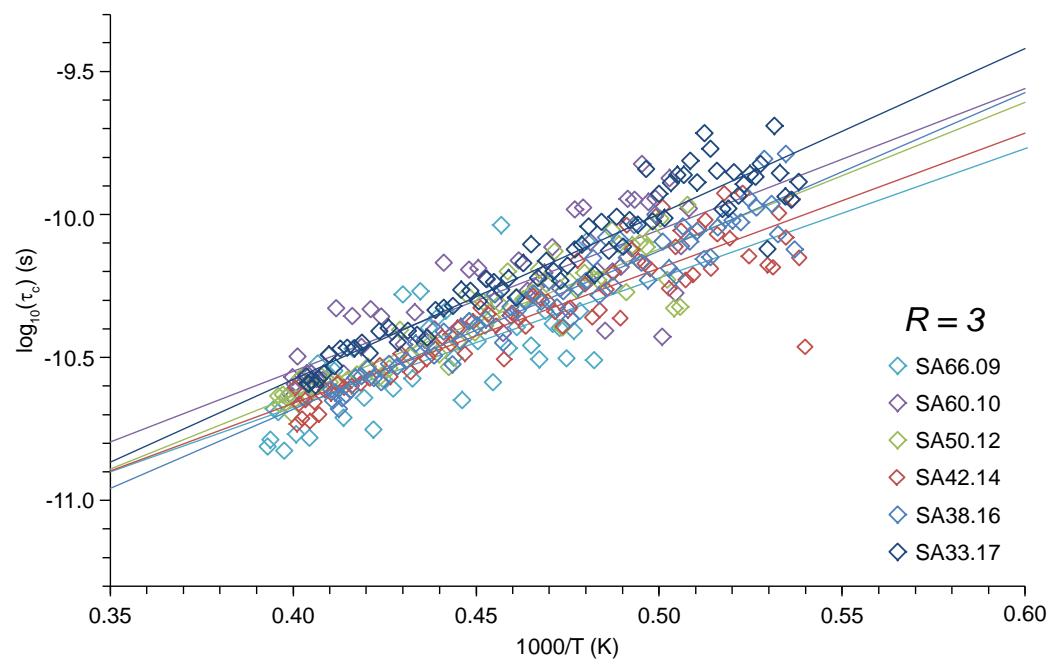

(c)

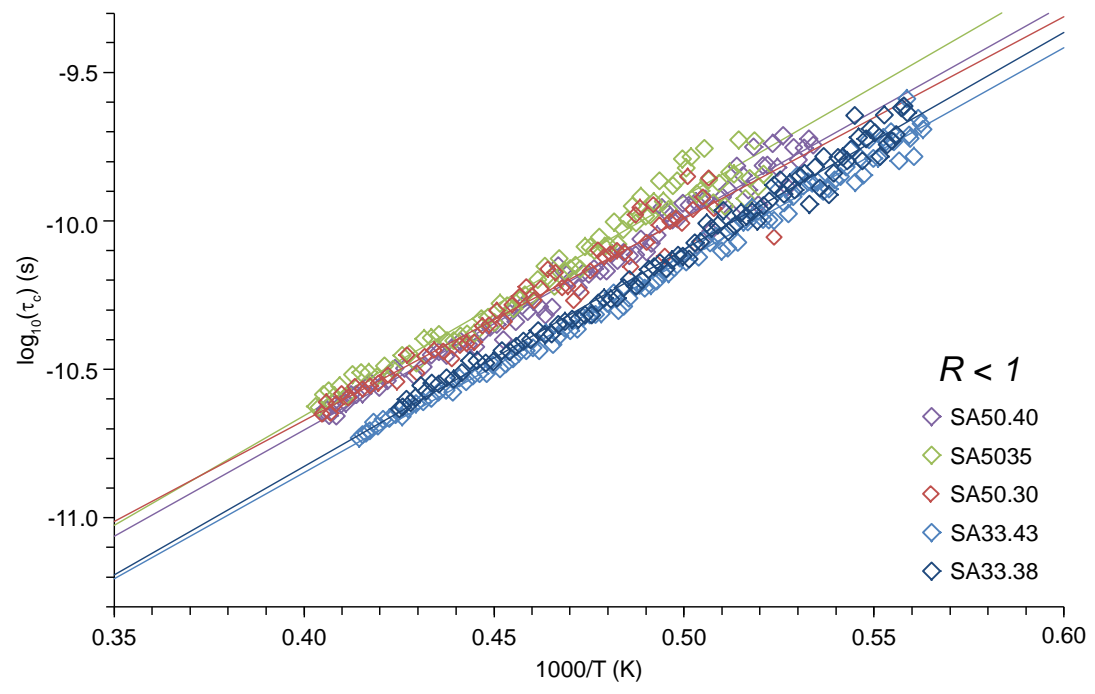

Figure 5. Evolution of the ${ }^{27} \mathrm{Al}$ NMR correlation times during free cooling of all compositions studied: (a) on the charge-compensation line $(R=1)$, (b) in the per-alkaline field $(R=3)$ and $(\mathrm{c})$ in the per-aluminous region $(R<1)$. 
Figure 5 presents the evolution of $\log _{10}\left(\tau_{c}\right)$ for aluminum correlation times versus inverse temperature. There is a clear linear behavior for all compositions in our temperature range, pointing to an Arrhenius behavior of the latter. As directly seen from the linewidth, composition has a strong impact on the aluminum correlation times along the join $R=1$, does separate the two $\left[\mathrm{SiO}_{2}\right](33.3$ and $50.0 \% \mathrm{~mol}$ ) in the per-aluminous field but has no clear impact for compositions belonging to the join $R=3$. Correlation times $\tau_{c}$ are found to vary typically in the range $10 \mathrm{ps}$ to $250 \mathrm{ps}$. They increase with increasing $\left[\mathrm{SiO}_{2}\right]$ along the join $R=1$ as well as in the per-aluminous field. They with increasing temperature in all cases.

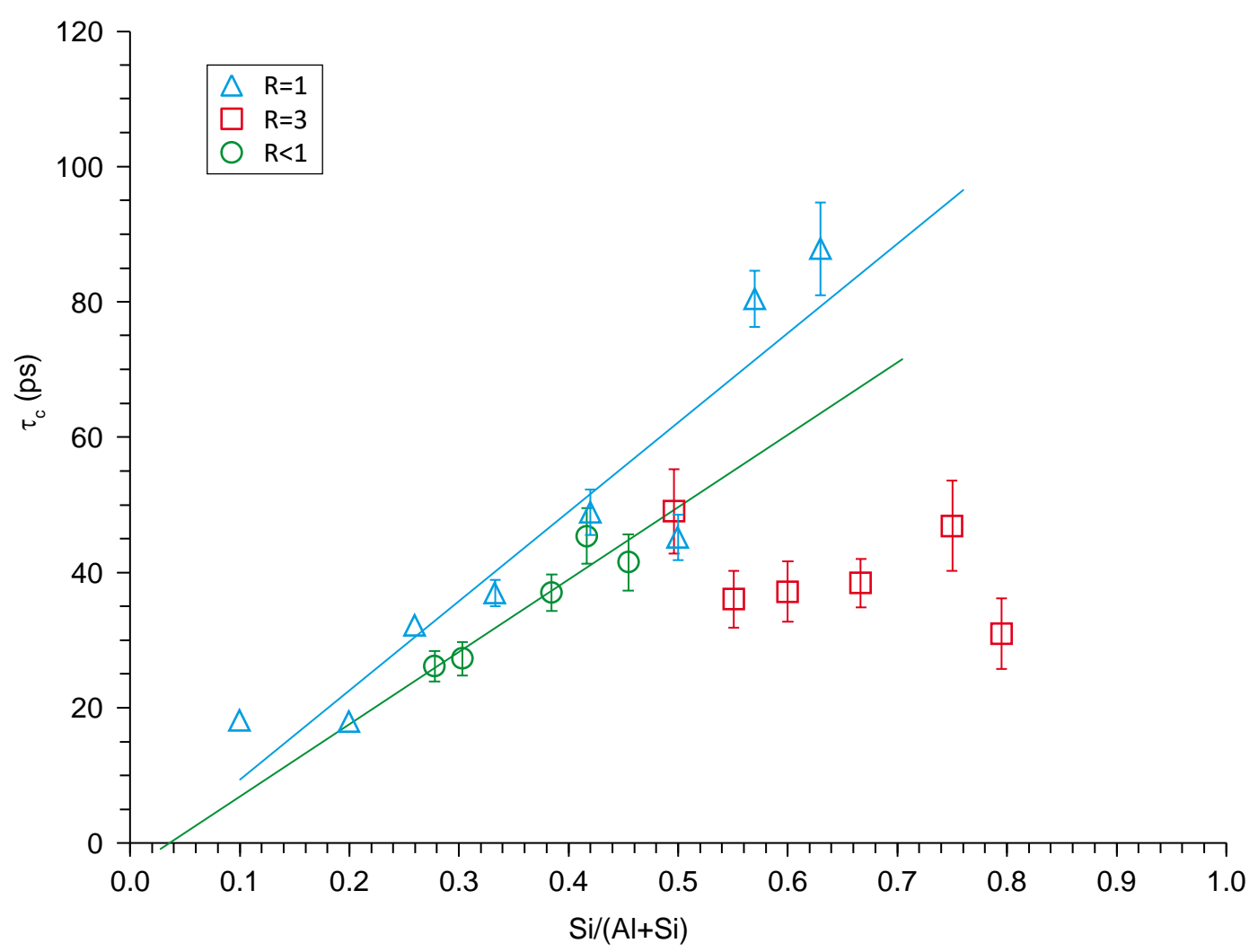

Figure 6. Evolution of the ${ }^{27} \mathrm{Al}$ NMR correlation time at $2000{ }^{\circ} \mathrm{C}$ for compositions $R=1$ (blue, triangles), $R=3$ (red, rectangles) and $R<1$ (green, circles). Error bars show the confidence intervals derived from the linear fit (figure 5) and lines are linear regressions.

This compositional dependence of the correlation time is evidenced by a plot of $\tau_{c}$ at $2000{ }^{\circ} \mathrm{C}$ as a function of the $\mathrm{Al} /(\mathrm{Al}+\mathrm{Si})$ ratio (figure 6). For this plot we used experimental temperature closest to $2000{ }^{\circ} \mathrm{C}$ and derived their predicted $\tau_{c}$ value using an exponential fit of the $\tau_{c}=\mathrm{f}(1 / \mathrm{T})$ evolution along with the related confidence interval for this selected point. The presence of NBOs

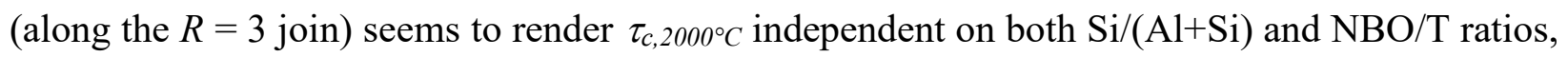
which are in the range $0.50-0.80$ and $0.99-2.44$ respectively. In the absence of NBOs, the ${ }^{27} \mathrm{Al}$ 
NMR correlation time increases linearly with increasing $\mathrm{Si} /(\mathrm{Al}+\mathrm{Si}), \tau_{c, 2000^{\circ} \mathrm{C}}$ is slightly lower in peraluminous compositions than at $\mathrm{R}=1$ but this is almost within the error bars of our measurement.

\section{Neutron Diffraction}

Due to the susceptibility of $\mathrm{SiO}_{2}$ to volatilise during the long counting times required for hightemperature neutron diffraction measurements, we studied only compositions containing up to 42 $\%$ mol and $33 \%$ mol of silica along the joins $\mathrm{R}=1$ and 3 respectively.

The total structure factors $S(Q)$ of all studied samples are presented in figure 2. As reported in table 2 for the compositions along both the composition lines $R=1$ and 3 , increasing the $\mathrm{SiO}_{2}$ content leads to a shift in the position $Q_{1}$ of the first peak (FSDP) in $S(Q)$ towards lower $Q$ values with a corresponding increase in peak height. This indicates that the degree of intermediate-range order is improved by incorporating silica into the structure. As observed with calcium aluminosilicate compositions, this shift, which is expected with the increase of the silica concentration, could be also a signature of the increase of the ring size (Hennet et al., 2016). As seen in table 2, for the same silica content the $Q_{1}$ values are higher for $R=3$ than for $R=1$. Hence, this seems to show that the ring size becomes smaller when the $\mathrm{SrO}$ content is increased, consistent with a higher fraction of NBO.

The total pair distribution function is calculated from the structure factor by the Fourier transform:

$$
g(r)-1=\frac{1}{2 \pi^{2} r \rho_{0}} \int_{0}^{\infty}[S(Q)-1] Q \sin (Q r) d Q
$$

where $\rho_{0}$ denotes the atomic number density, estimated as $\sim 95 \%$ of the glass densities reported in our previous works (Charpentier et al., 2018). As there is no experimental data available at this time, this estimation is based on our work on CAS glasses and liquids (Hennet et al., 2016), which is a similar system. All values are listed in table 2.

\begin{tabular}{c|c|c|c|c|c} 
Sample & $\rho_{0}\left(\AA^{-3}\right)$ & $\mathrm{T}\left({ }^{\circ} \mathrm{C}\right)$ & $\mathrm{Q}_{1}\left(\AA^{-1}\right)$ & $\mathrm{r}_{\text {Al-O }}(\AA)$ & $\mathrm{CN}_{\text {Al-O }}$ \\
\hline SA20.40 & 0.0682 & 1750 & 2.03 & 1.756 & 4.06 \\
SA33.33 & 0.0691 & 1750 & 2.00 & 1.761 & 4.05 \\
SA42.29 & 0.0696 & 1850 & 1.95 & 1.766 & 4.06 \\
\hline SA20.20 & 0.0633 & 2050 & 2.13 & 1.758 & 4.06 \\
SA33.17 & 0.0663 & 1750 & 2.08 & 1.763 & 4.05 \\
\hline
\end{tabular}

Table 2, Summary of the structural parameters obtained from neutron diffraction for all measured samples. 
Figure 7 shows the total pair distribution functions $g(r)$ for all the compositions studied along the joins $R=1$ and $R=3$. In all cases, the first peak corresponds to an overlapped contribution from both the $\mathrm{Si}-\mathrm{O}$ and the $\mathrm{Al}-\mathrm{O}$ nearest neighbor pairs. Its position shifts gradually toward the $\mathrm{Si}$ $\mathrm{O}$ bond distance with increasing $\mathrm{SiO}_{2}$ concentration. As shown in figure 8(a), for compositions containing $33 \%$ of silica taken as an example, the $\mathrm{Si}-\mathrm{O}$ and $\mathrm{Al}-\mathrm{O}$ local environment in the liquid and the corresponding glass are very similar. However, an increase in the fraction of $\mathrm{AlO}_{5}$ units is found in the melts, as indicated by a more pronounced shoulder on the high $r$ part of the first peak in $g(r)$.

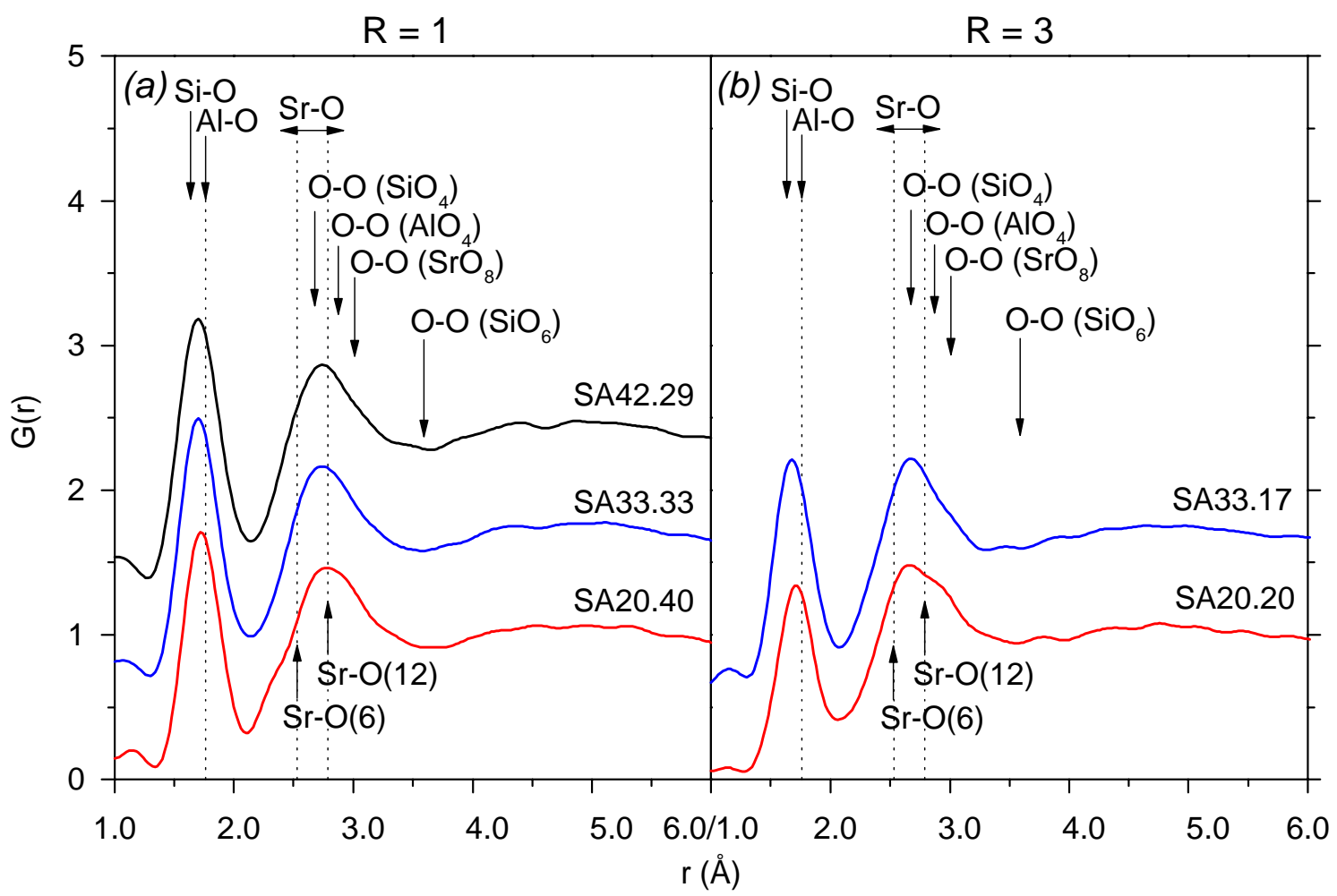

Figure 7. Total pair distribution functions $g(r)$ for the liquid SAS along the composition lines $\mathrm{R}=1$ (a) and $\mathrm{R}=3$ (b). The positions of the various correlations are shown as a guide. $\mathrm{O}-\mathrm{O}$ correlations are calculated assuming $\mathrm{SiO}_{4}, \mathrm{AlO}_{4}$, $\mathrm{SrO}_{6}$ and $\mathrm{SrO}_{8}$ polyhedra.

Coordination numbers and bond distances were determined by making Gaussian fit to the correlation function $T(r)=4 \pi r \rho_{0} g(r)$ as described by (Hennet et al., 2016) in the case of liquid calcium aluminosilicates. The Gaussian fit was performed by fixing the coordination number of the Si-O bond to 4 leading to a bond length of $1.65 \AA$ similar to what has been found with CAS compositions (Hennet et al., 2016). The fits are shown in figure 8(b) for all compositions studied by neutron diffraction and the results for the Al-O correlations are summarized in table 2. For all 
samples, the average $\mathrm{Al}$ coordination number is found to be close to 4 . Despite the relatively large error value of \pm 0.5 , a fraction of $5-6 \% \mathrm{AlO}_{5}$ units is estimated in the liquid state for all compositions, in agreement with $\mathrm{AlO}_{5}$ fractions found in the related glasses (Novikov et al., 2017).

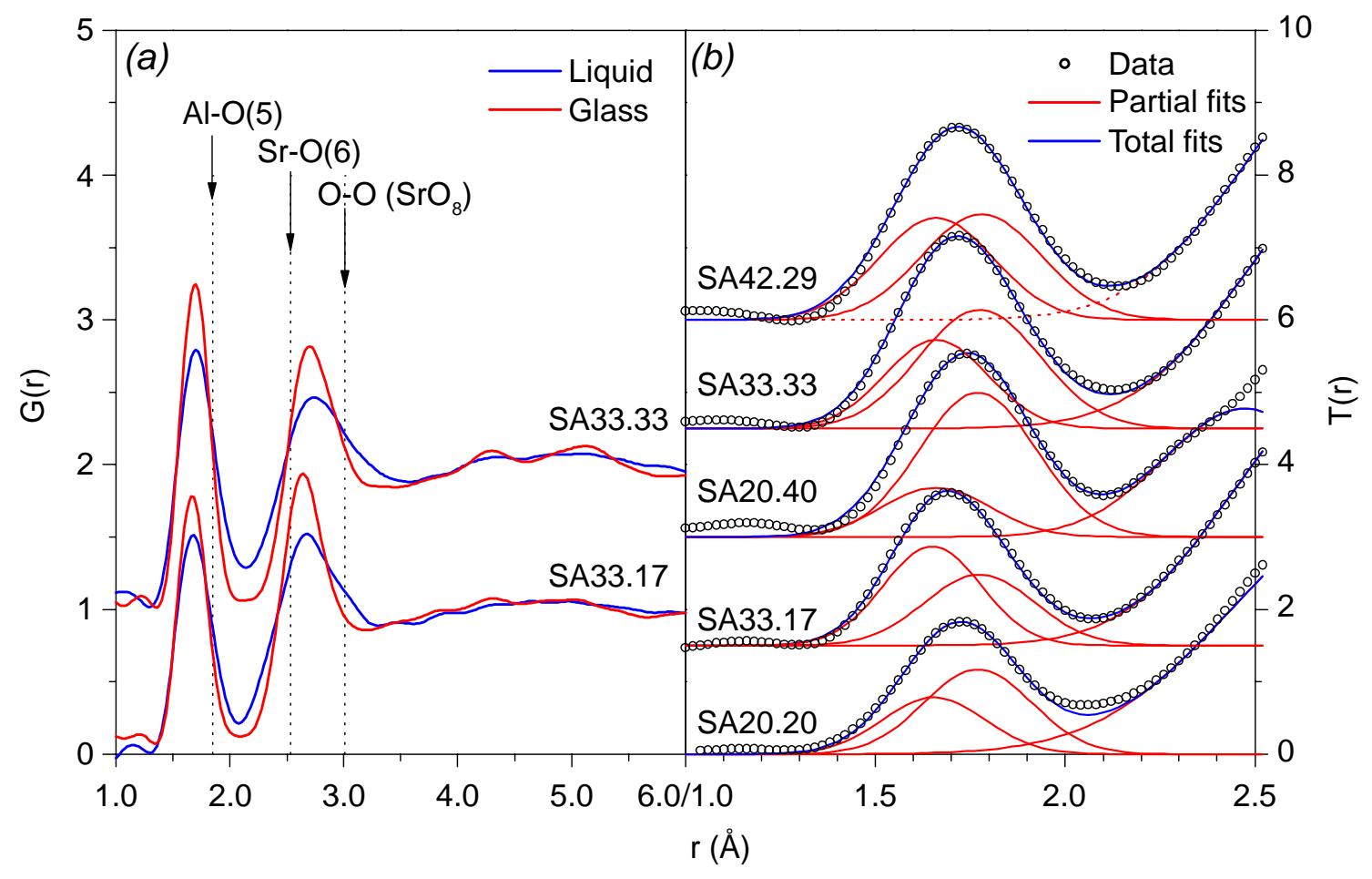

Figure 8. (a) Total pair distribution functions $g(r)$ in the liquid and glassy states for the two samples SA33.33 and SA33.17. (b) Total correlation function $T(r)$ for all studied compositions along the joins $\mathrm{R}=1$ and 3 . The partial and total are shown in comparison to the experimental data.

The short-range order around $\mathrm{Sr}$ is more difficult to study as $\mathrm{Sr}-\mathrm{O}$ correlations are completely overlapped by the contributions of the O-O pairs arising from Si-O and Al-O tetrahedra and highly coordinated Sr-O polyhedra $(\mathrm{CN} \geq 7)$. Considering the $g(r)$ functions in figure $8 \mathrm{a}$, it seems that the $\mathrm{Sr}$ environment is more complex in the liquid than in the glass. On the one hand, a first Sr-O contribution is present at distances shorter than $2.53 \AA$ (typical for $\mathrm{SrO}_{6}$ ), meaning that $\mathrm{Sr}-\mathrm{O}$ with coordination less than 6 should be present. On the other hand, all pair distribution functions also exhibit also a peak at $\sim 3.0 \AA$ corresponding to O-O distances in $\mathrm{SrO}_{8}$ polyhedra. For the join $R=$ 1, some correlations observed between $3.0 \AA$ and $3.6 \AA$ could be attributed to O-O bonds for 7-fold coordinated Sr. Then compared to the glass compositions in which the $\mathrm{Sr}-\mathrm{O}$ coordination number has been estimated between 8.5 and 9.0 (Charpentier et al., 2018; Novikov et al., 2017), in the liquid state the coordination number is expected to be around 8 for the join $\mathrm{R}=3$ and somewhat 
less for $\mathrm{R}=1$. This lowering is currently difficult to quantify since we cannot observe all pair correlations.

\section{Discussion}

Figure 9 presents an overview of the ${ }^{27} \mathrm{Al}$ chemical shifts observed in molten droplets at 2000 ${ }^{\circ} \mathrm{C} \delta_{2000^{\circ} \mathrm{C}}$ and centers of gravity $<\delta_{\text {iso }}>_{\text {glass }}$ of the ${ }^{27} \mathrm{Al}$ MAS NMR spectra obtained on related glasses versus $\mathrm{Si} /(\mathrm{Al}+\mathrm{Si})$. Both $R=1$ and $R=3$ joins show a linear evolution (figure $\mathrm{S} 2$ and $\mathrm{S} 3$ report versus $\left[\mathrm{SiO}_{2}\right]$ and $\left[\mathrm{Al}_{2} \mathrm{O}_{3}\right]$ respectively). Here "center of gravity of the MAS NMR spectra" means the average between $\delta_{i s o}\left({ }^{V} A l\right)$ and $\delta_{i s o}\left({ }^{V} A l\right)$ weighted by the ${ }^{\mathrm{IV}} \mathrm{Al}$ and ${ }^{\mathrm{V}} \mathrm{Al}$ populations respectively, as derived from the simulations of the MAS spectra of the glasses (Charpentier et al., 2018; Novikov et al., 2017).

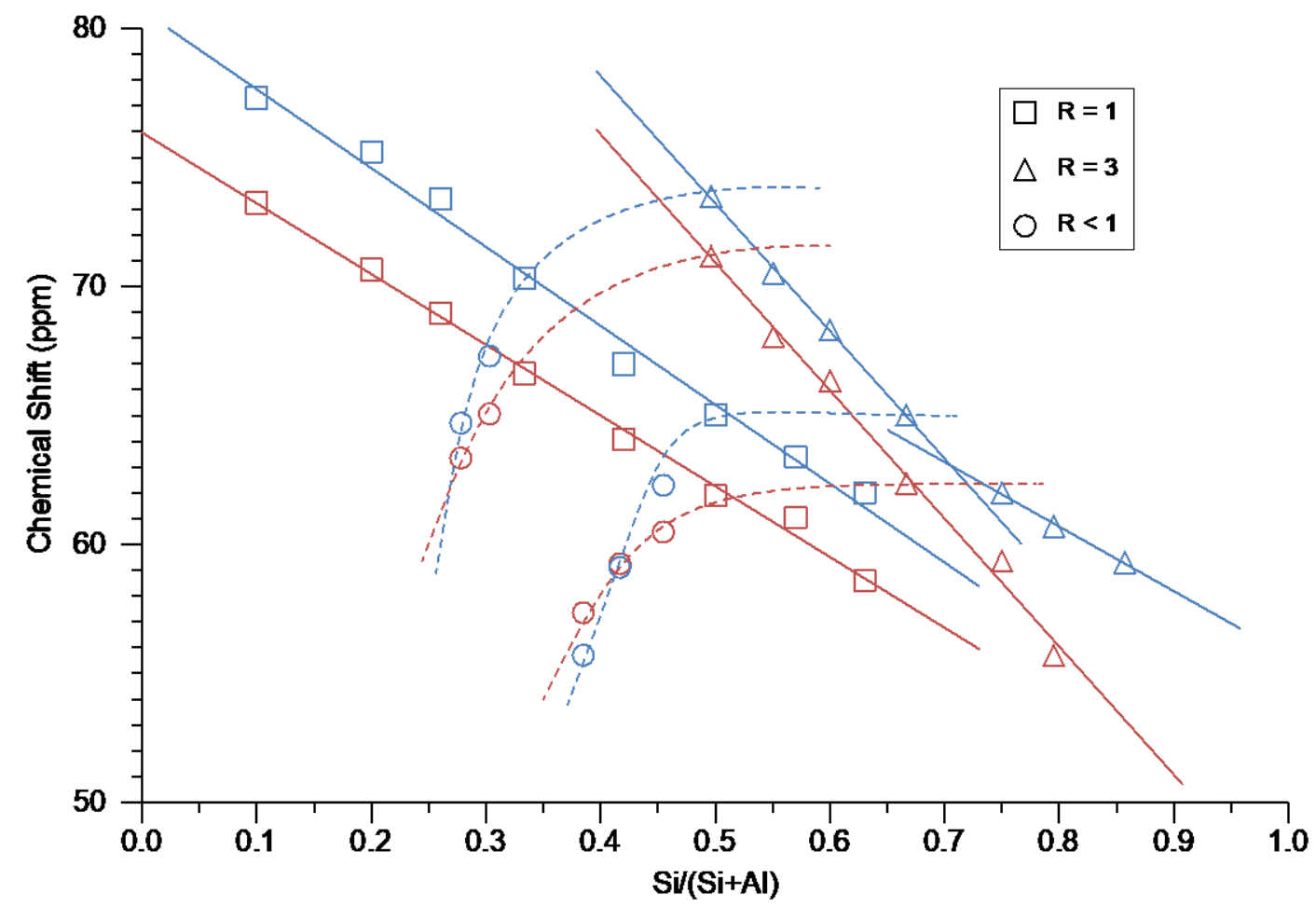

Figure 9. ${ }^{27} \mathrm{Al}$ chemical shifts at $2000^{\circ} \mathrm{C} \delta_{2000^{\circ} \mathrm{C}}$ (red) and "barycenter" of the glass spectra $\left\langle\delta_{\text {iso }}>_{\text {glass }}\right.$ see text for details) (blue) for $R=1$ (rectangles), $R=3$ (triangles) and $R<1$ (circles) compositions. Continuous lines are linear fit, dashed ones are guides for the eyes for $\left[\mathrm{SiO}_{2}\right]=33 \%$ (top) and $\left[\mathrm{SiO}_{2}\right]=50 \%$ (bottom).

For the $R=1$ compositions we observe a linear evolution of the ${ }^{27} \mathrm{Al}$ chemical shift at $2000{ }^{\circ} \mathrm{C}$ $\left(\delta_{2000^{\circ} \mathrm{C}}\right)$ versus $\mathrm{Si} /(\mathrm{Si}+\mathrm{Al})$, with a slope of $-27.4 \pm 0.8 \mathrm{ppm} / \mathrm{mol} \%$. This is comparable to the value of $-30.6 \pm 1.2 \mathrm{ppm} / \mathrm{mol} \%$ observed for the evolution of $\left\langle\delta_{\text {iso }}>_{\text {glass }}\right.$ and $-28.0 \mathrm{ppm} / \mathrm{mol} \%$ (Charpentier et al., 2018) for $\delta_{i s o}\left({ }^{V} A l\right)_{\text {glass. }}$ The evolution in the melt can therefore be ascribed, like 
in the glass (Charpentier et al., 2018), to the progressive substitution of $\mathrm{Al}$ by $\mathrm{Si}$ in the second aluminum coordination sphere upon increasing $\mathrm{Si} /(\mathrm{Si}+\mathrm{Al})$, favoring the $\mathrm{Al}-\mathrm{O}-\mathrm{Si}$ linkages. It leads to an average of $-7.1 \mathrm{ppm} / \mathrm{substitution}$ for the melt and $-7.8 \mathrm{ppm}$ for the glass. Our Neutron diffraction results confirm that the amount of ${ }^{\mathrm{V}} \mathrm{Al}$ is only a few percent, like in the glass, and will hence not significantly influence the melt's aluminum chemical shifts for the $R=1$ and 3 joins.

For the join $R=3$ compositions, the $\left\langle\delta_{i s o}>_{\text {glass }}\right.$ is a combination of two linear function of $\mathrm{Si} /(\mathrm{Si}+\mathrm{Al})$ with: a slope of $-49.3 \pm 1.2 \mathrm{ppm} / \mathrm{mol} \%$ below $\mathrm{Si} /(\mathrm{Al}+\mathrm{Si}) \sim 0.7$ and $-25.2 \pm 2.5 \mathrm{ppm} /$ mol\% above. If the slope at high silica content matches the slope found for $R=1$ and hence points to a progressive substitution of $\mathrm{Si}$ by $\mathrm{Al}$, the more negative slope at low silica content shows the existence of an additional mechanism. Since depolymerization of the aluminum units has been shown to produce an increase of $\delta_{i s o}\left(A l^{I V}\right)$ in calcium aluminosilicate glasses (Neuville et al., 2006) and that gehlenite $\mathrm{Ca}_{2} \mathrm{Al}_{2} \mathrm{SiO}_{7}$ shows a $\delta_{\text {iso }}$ difference of +11 ppm between an $\mathrm{AlO}_{4}-\left(\mathrm{Al}_{2} \mathrm{Si}_{2}\right)$ and an $\mathrm{AlO}_{4}-\left(\mathrm{Al}_{2} \mathrm{Si}\right)$ configuration (Florian et al., 2012), the two compositional behavior of $\left\langle\delta_{\text {iso }}>\right.$ glass can be understood as the formation of $\mathrm{NBO}$ on the $\mathrm{AlO}_{4}$ units below $\mathrm{Si} /(\mathrm{Al}+\mathrm{Si}) \sim 0.7$. This finding in the glassy state is in excellent agreement with ${ }^{17} \mathrm{O}$ NMR measurements on CAS glasses (Allwardt et al., 2003) predicting a disappearance of Al-NBO for compositions richer in $\mathrm{SiO}_{2}$ than CAS33, i.e. above $\mathrm{Si} /(\mathrm{Al}+\mathrm{Si})=0.67$. A striking difference with the evolution in the melt is that the entire compositional range explored is characterized by a single slope of $-49.6 \pm 2.2 \mathrm{ppm} /$ mol $\%$ consistent with the presence of $\mathrm{NBOs}_{\text {on }} \mathrm{AlO}_{4}$ over the full compositional range, a behavior also seen in our Molecular Dynamics simulations (Charpentier et al., 2018). Keeping in mind that at high silica content a low ${ }^{27} \mathrm{Al}$ NMR signal-to-noise ratio (low alumina content) produces an increased uncertainty on the in-situ measurements, this suggests that $\mathrm{NBOs}$ on $\mathrm{AlO}_{4}$ present in the high temperature per-alkaline melts can be fully lost in the glass for high-silica compositions while they are kept at lower silica content. Our finding suggests that, near $\mathrm{T}_{\mathrm{g}}$, high concentration of silica favors the polymerization of the melt around $\mathrm{Al}[\mathrm{O}(\mathrm{Al}, \mathrm{Si})]_{4}$ species for which $\delta_{i s o}$ is solely controlled by the $\mathrm{Si} /(\mathrm{Al}+\mathrm{Si})$ ratio, similarly to the join $R=1$.

For both joins the chemical shifts obtained in the melts are lower than the ones derived from the glasses, a consequence of both thermal (decrease of Al-O distances) and structural (increase in average Al coordination) effects. Thermal effects are difficult to evaluate as they are a combination of thermal expansion and quantum quasiharmonic vibrations (Nemausat et al., 2015) difficult to disentangle and producing counter-intuitive, coordination-dependent, evolutions with temperature. 
But since our Neutron diffraction measurements points to [ $\left.{ }^{\mathrm{V}} \mathrm{Al}\right]$ in the melts close to the one in the glasses, the dominant mechanisms at the origin of this downward shift from glass to melt is thermal expansion.

The $R<1$ compositions explore two constant [ $\left.\mathrm{SiO}_{2}\right]$ ranges (horizontal lines in figure 1) with varying $\mathrm{Sr} / \mathrm{Al}$ ratio and their $\delta_{i s o}$ do not show linear correlations with composition. At fixed $\left[\mathrm{SiO}_{2}\right]$ we observe a marked decrease of both $\left\langle\delta_{\text {iso }}\right\rangle_{\text {glass }}$ and $\delta_{2000^{\circ} \mathrm{C}}$ upon crossing the $R=1$ join that correlates with the presence of significant amounts of higher coordination states of aluminum $\left({ }^{\mathrm{V}} \mathrm{Al}\right.$ and even ${ }^{\mathrm{VI}} \mathrm{Al}$ ) in the corresponding glasses (evidenced by ${ }^{27} \mathrm{Al}$ MAS NMR experiments, see figure S4). The chemical shift difference between $\left\langle\delta_{i s o}\right\rangle_{\text {glass }}$ and $\delta_{2000^{\circ} \mathrm{C}}$ is now down to an average of $0.6 \mathrm{ppm}$ which suggests that the structure of those compositions are less prone to temperature effects than the one on the joins $R=3$ and $R=1$. Yet there seems to be a cross-over between glass and melt evolutions (see crossing dashed lines in figure 9) pointing to the presence of various competing mechanisms affecting $\delta_{2000^{\circ} \mathrm{C}}$ at low silica content: thermal expansion, aluminum average coordination, $\mathrm{NBOs}$ on $\mathrm{AlO}_{4}$ units as seen before, but also the possible presence of tricoordinated oxygen involving $\mathrm{AlO}_{5}$ units. 


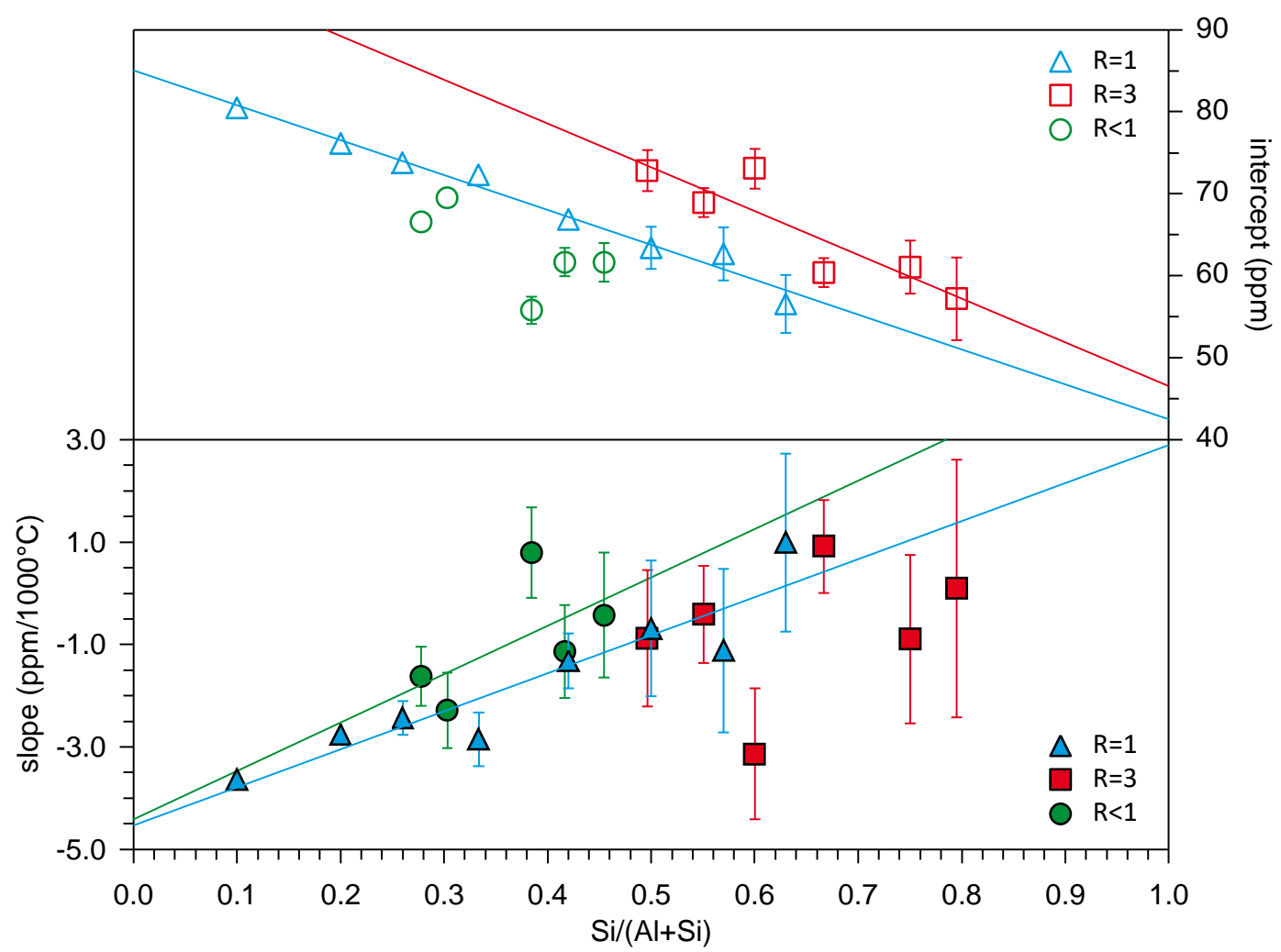

Figure 10. Evolution of the slope (bottom) and intercept (top) of the $\delta_{i s o}=f(T)$ of the linear regressions for compositions $R=1$ (triangles), $R=3$ (rectangles) and $R<1$ (circles). Error bars show $95 \%$ confidence intervals (within symbol when not shown) and lines are linear regressions.

The time-resolved acquisition of ${ }^{27} \mathrm{Al}$ during free cooling also provides measurements of $\delta=$ $f(T)$ (figure 4) that traces the evolution with temperature of the average structure of the melt viewed by aluminum. Slopes $\partial \delta / \partial T$ and intercepts $\delta(0)$ of the $\delta=f(T)$ extracted from the linear regression on the data points (figure 4 ) are given in table 1 and displayed in figure 10 as a function of the $\mathrm{Si} /(\mathrm{Al}+\mathrm{Si})$ ratio.

This $\partial \delta / \partial T$ slope represents the temperature dependence of the average local aluminum structure. When the fragility $m=\left(\frac{\partial \log _{10} \eta}{\partial\left(T_{g} / T\right)}\right)_{T=T_{g}}$ where $\eta$ is the viscosity (Angell, 1988) measures the thermal dependence of the structure at $\mathrm{T}_{\mathrm{g}}$, our $\partial \delta / \partial T$ results provide similar insights at temperature larger than $2 T_{g}$. A link between $\partial \delta / \partial T$ and glass forming ability has been formerly observed in calcium aluminates (Massiot et al., 2008; Neuville et al., 2010). In this case all compositions forming glasses showed values of $\partial \delta / \partial T$ below $-2 \mathrm{ppm} / 1000^{\circ} \mathrm{C}$ whereas non-glass forming ones where found above this threshold. 
Here we observe an increase of $\partial \delta / \partial T$ with increasing $\mathrm{Si} /(\mathrm{Al}+\mathrm{Si})$ with a close-to-linear and common behavior for all compositions. This shows that $\mathrm{Si} /(\mathrm{Al}+\mathrm{Si})$, i.e. the distribution of $\mathrm{Al}$ $(\mathrm{OSi})_{\mathrm{p}}(\mathrm{OAl})_{(4-\mathrm{p})}$ units, is the dominant parameter that controls the temperature dependence of the aluminum environment. This can be related to the temperature dependence of the melt viscosity seen in fully polymerized systems by Molecular Dynamic simulations (Scamehorn and Angell, 1991) and for which the fragility increases with increasing Al/Si ratio. Interestingly, neither the presence of high-coordinated aluminum species $(R<1)$ nor that of Si-NBOs or Al-NBOs $(R=3)$ seems to have a dramatic effect on $\partial \delta / \partial T$. It shows that the ability of aluminum to adjust its local structure to temperature changes is controlled by the network connectivity. The behavior of the intercept, i.e. the extrapolation of $\left\langle\delta_{i s o}>\right.$ evolution at $0{ }^{\circ} \mathrm{C}$, mimics the evolution seen for $\delta_{2000^{\circ} \mathrm{C}}$ (figure 9), showing a structural continuity between the high-temperature melt and the glassy state.

The Arrhenian behavior of the ${ }^{27} \mathrm{Al}$ NMR correlation times as a function of temperature allows deriving an activation energy $E_{a}$ and pre-exponential factor $\tau_{0}$ which are shown as a function of composition in figure 11. As already inferred from the evolutions of $\tau_{c}$ itself (figure 5) the NBOcontaining compositions $(R=3)$ depart from the others. When $R \leq 1$ compositions show a constant activation energy around $140 \mathrm{~kJ} / \mathrm{mol}$ and a frequency factor in the range 0.01 ps to $0.04 \mathrm{ps}, R=3$ ones display $E_{a} \sim 100 \mathrm{~kJ} / \mathrm{mol}$ and $\tau_{0} \sim 0.03 \mathrm{ps}$ to $0.23 \mathrm{ps}$. Those values of activation energies are fully consistent with the $\sim 135 \mathrm{~kJ} / \mathrm{mol}$ obtained on a glass of albite composition $\left(\mathrm{NaAlSi}_{3} \mathrm{O}_{8}\right)$ above $T_{g}$ by ${ }^{29} \mathrm{Si}$ NMR (Farnan and Stebbins, 1990) but much lower than the values of $215 \mathrm{~kJ} / \mathrm{mol}$ and $258 \mathrm{~kJ} / \mathrm{mol}$ obtained by high-temperature shear viscosity measurements in SA26.37 and SA50.25 melts respectively (Urbain et al., 1982). We can also note that our measurement fall below the 257 $\mathrm{kJ} / \mathrm{mol}$ - $985 \mathrm{~kJ} / \mathrm{mol}$ range of activation energies for shear viscosity found in calciumaluminosilicate melts (Toplis and Dingwell, 2004). 


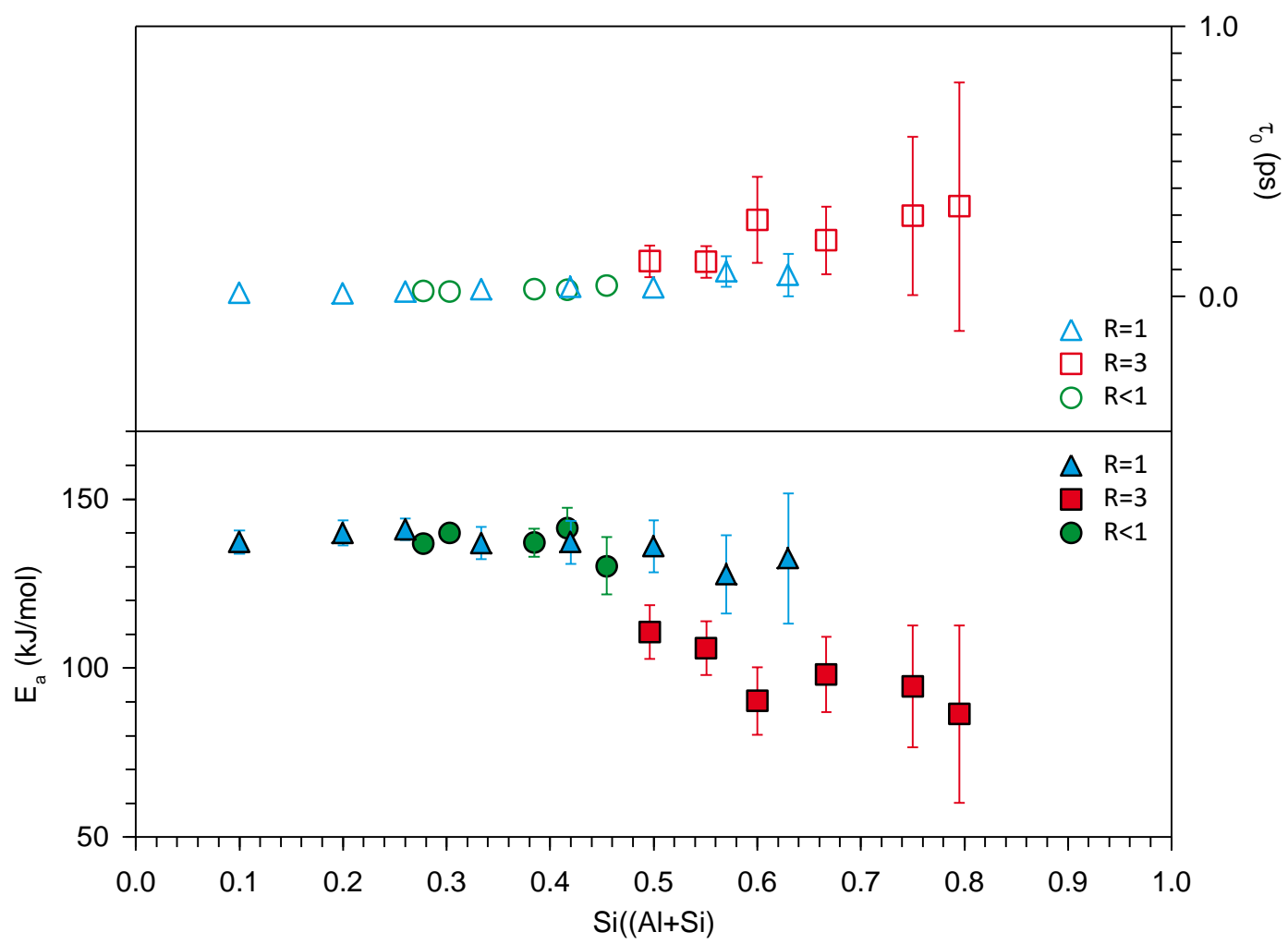

Figure 11. Evolution of the activation energy $E_{a}$ (bottom) and pre-exponential ('frequency') factor $\tau_{0}$ of the ${ }^{27} \mathrm{Al} \mathrm{NMR}$ relaxation for compositions $R=1$ (triangles), $R=3$ (rectangles) and $R<1$ (circles). Error bars show 95\% confidence intervals (within symbol when not shown).

The correlation time for shear viscosity can be obtained using Maxwell equation $\tau_{s}=\eta / G_{\infty}$, where $\eta$ is the shear viscosity and $G_{\infty}=10^{10 \pm 0.5} \mathrm{~Pa}$ the infinite frequency shear modulus (Dingwell and Webb, 1990). We previously compared those with the NMR-derived $\tau_{c}$ and have found in the case of aluminosilicate compositions agreements for calcium-aluminosilicates (Gruener et al., 2001) but strong mismatch for yttrium-aluminosilicates (Florian et al., 2007). We performed low-temperature viscosity measurements on all compositions (Novikov et al., 2017) but the only high-temperature viscosity measurements available to us for strontium-aluminosilicates are those of Urbain (Urbain et al., 1982) obtained on only two compositions. They are compared to the NMR correlation times in figure 12 . 


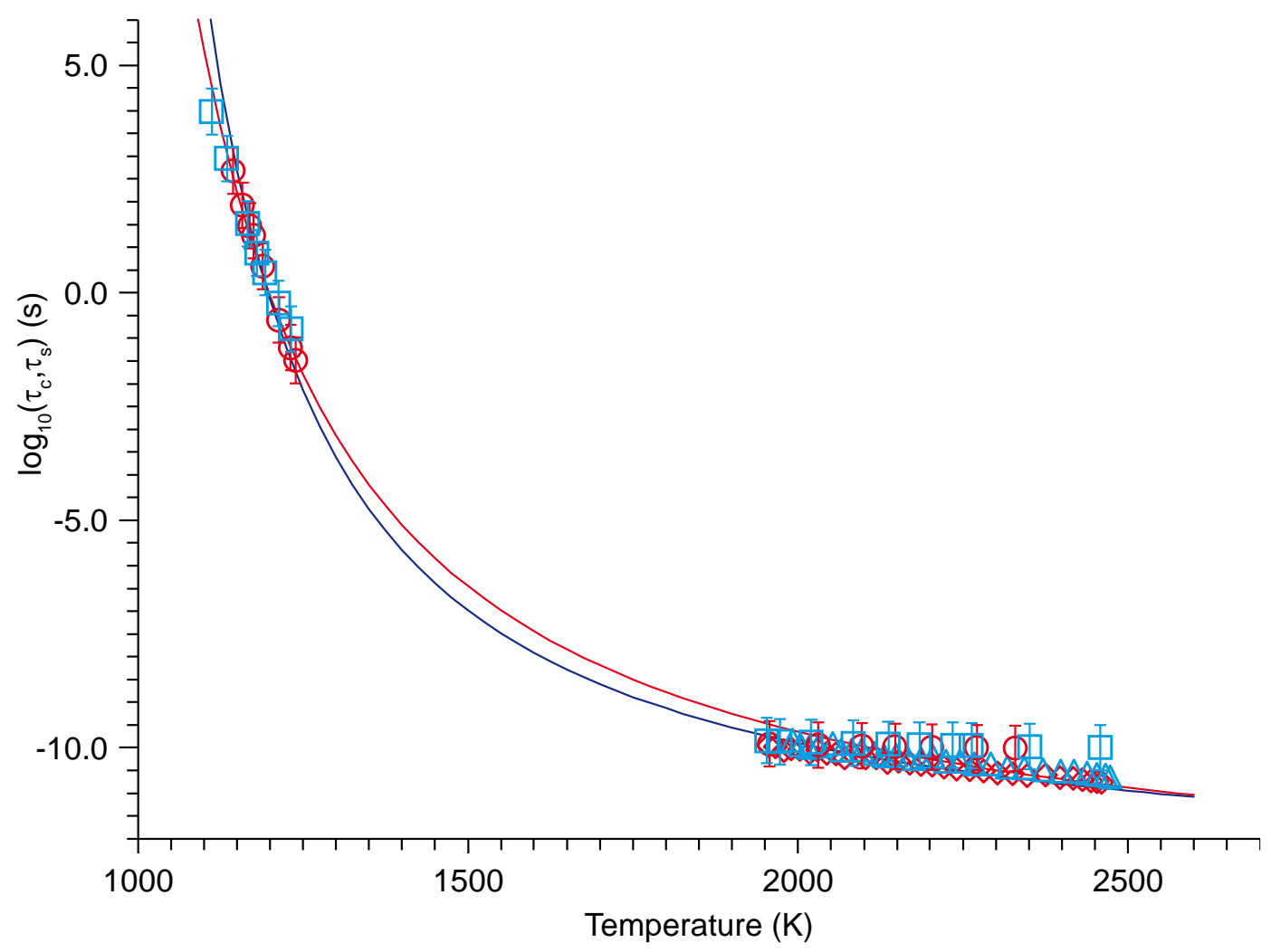

Figure 12. Correlation times derived from NMR (triangles and diamonds) and shear viscosity (squares and circles) as a function of temperature and for the compositions SA50.25 (blue) and SA26.37 (red). Only one in two NMR data points are drawn for clarity purposes. Lines are fits using the VTF equation with HT NMR and LT viscosity data (see text for details).

The correlation times derived by the two techniques are in very good agreement considering the error on $G_{\infty}$ which leads to an uncertainty of \pm 0.5 on $\log _{10}\left(\tau_{s}\right)$. It is highly improbable that $\mathrm{AlO}_{\mathrm{n}}$ units exist in melts for a long enough period of time to consider their translational and rotational diffusion (Liu et al., 1988; Stebbins, 2016). As a consequence, the ${ }^{27}$ Al NMR relaxation from which we derived $\tau_{c}$ and $E_{a}$ happens through vibrations of the Al-O bonds and probes dynamics close to the Larmor frequency. Since the melt' shear viscosity is expected to be controlled by the oxygen diffusion (Dingwell and Webb, 1990), the correspondence between $\tau_{c}$ and $\tau_{s}$ shows a coupling between the Al-O vibrations at the origin of the NMR relaxation and the oxygen self-diffusion coefficient $D$ linked to the shear viscosity through the Eyring equation $D=$ $k_{B} T / \eta \lambda$.

The origin of the coupling can be found in random walk theory of activated diffusion where the diffusion coefficient is related to the average square jump length $\left\langle\lambda^{2}\right\rangle$, the average jump frequency $\Gamma$ and a geometric factor $\gamma$ (1/6 for unrestricted motion in three dimensions) through the equation 


$$
D=\gamma\left\langle\lambda^{2}\right\rangle \Gamma
$$

In the case of random motion of a diffusing atom over a potential barrier, $\Gamma$ has been expressed as:

$$
\Gamma=v e^{-\Delta G / k_{B} T}
$$

where $v$ is the frequency of vibration of the atom around its equilibrium position and $\Delta G$ is the "free energy of activation" (Perkins and Begeal, 1971; Wert, 1950; Zener, 1951). The (Debye) frequency $v$ is on the order of $10^{12}-10^{13} \mathrm{~Hz}$ and is at the origin of the time-modulation of the NMR interaction responsible for NMR relaxation. In the derivation of Zener (Zener, 1951), $\Delta G$ is the work required to produce a lattice's distortion allowing the jump and then $\Delta H$ is the measured activation energy of diffusion (retrieved by plotting $\ln (D)$ as a function of $1 / \mathrm{T}$ ) which in transition state theory is often equated with the sum of the energy required to launch a species for a diffusive jump and the energy needed to form a landing site for the species.

At high enough temperature $e^{-\Delta G / k_{B} T}$ goes to unity and the oxygen vibrations $v$ becomes the jump frequency $\Gamma$ (equation (6)) leading to a coupling of oxygen diffusivity and NMR relaxation through equation (5). Practically this is seen at $T / T_{g} \geq 2$ but only for the most fragile liquids.

Using $\Gamma=v=1 / \tau_{c, 2000^{\circ} \mathrm{C}} \lambda=2.8 \AA$ (twice the oxygen ionic radius) and $\gamma=1 / 6$ equation (5) leads to $D$ in the range 130 to $75010^{-12} \mathrm{~m}^{2} / \mathrm{s}$. This range is difficult to compare with tracer diffusion measurements in aluminosilicate melts as a wide scattering in the measurements is found in the literature, spanning several orders of magnitude. For anorthite $\mathrm{CaAl}_{2} \mathrm{Si}_{2} \mathrm{O}_{8}$ melt (CA40.20 in our notation) at $2000^{\circ} \mathrm{C}$ and $1 \mathrm{~atm}$, "reliable" values of $1510^{-12} \mathrm{~m}^{2} / \mathrm{s}, 26410^{-12} \mathrm{~m}^{2} / \mathrm{s}$ and $82310^{-12} \mathrm{~m}^{2} / \mathrm{s}$ have been reported (Dunn, 1982). With this in mind, the compositional evolution of the aluminum NMR $\tau_{c}$ at $2000^{\circ} \mathrm{C}$ displayed in figure 6 can be viewed as a decrease of oxygen diffusivity $D$ with increasing $\mathrm{Si} /(\mathrm{Al}+\mathrm{Si})$ ratio for polymerized melts from $74810^{-12} \mathrm{~m}^{2} / \mathrm{s}$ (SA20.40) down to $1311^{-}$ ${ }^{12} \mathrm{~m}^{2} / \mathrm{s}$ (SA57.21), whereas depolymerized melts $(R=3)$ have oxygen diffusivity of approximately $310 \pm 10010^{-12} \mathrm{~m}^{2} / \mathrm{s}$ and no clear compositional dependence. This can also be viewed as evolution of the viscosity of those melts since $D$ is inversely proportional to $\eta$ according to the Eyring equation. Note that for $\mathrm{Si} /(\mathrm{Al}+\mathrm{Si})>0.5$ the higher values of $\tau_{c}$ at $2000^{\circ} \mathrm{C}$ obtained on the polymerized compositions (SA57.21 and SA63.18) with respect to the depolymerized ones (figure 6) translate into lower oxygen self-diffusion coefficient and higher viscosity, as expected. 


\section{Conclusions}

We have been investigating the $\mathrm{SrO}-\mathrm{Al}_{2} \mathrm{O}_{3}-\mathrm{SiO}_{2}$ ternary system in the high temperature melt using in-situ NMR and Neutron diffraction techniques and exploring depolymerized $\left([\mathrm{SrO}] /\left[\mathrm{Al}_{2} \mathrm{O}_{3}\right]=3\right)$, fully polymerized $\left([\mathrm{SrO}] /\left[\mathrm{Al}_{2} \mathrm{O}_{3}\right]=1\right)$ and per-aluminous $\left([\mathrm{SrO}] /\left[\mathrm{Al}_{2} \mathrm{O}_{3}\right]<1\right)$ compositions with temperature typically in the range $1600{ }^{\circ} \mathrm{C}-2300^{\circ} \mathrm{C}$.

In terms of structure, we found that the high-temperature melt structure follows that of related glasses to a reasonable extent. Low amounts of ${ }^{\mathrm{V}} \mathrm{Al}$ species are found in the polymerized melts, in agreement with our finding in the glasses. The structure of the polymerized melts is controlled by the close-to-random distribution of $\mathrm{Al}$ and $\mathrm{Si}$ in the tetrahedral sites of the aluminosilicate network. In contrast to this, the depolymerized glasses exhibit NBOs on the $\mathrm{AlO}_{4}$ units only below $\mathrm{Si} /(\mathrm{Al}+\mathrm{Si}) \sim 0.7$ whereas the evolution of the melts is consistent with the presence of NBOs on $\mathrm{AlO}_{4}$ over the full compositional range. Within our measurements uncertainties, this suggests that NBOs on $\mathrm{AlO}_{4}$ present in the high temperature per-alkaline melts can be fully lost during cooling for high-silica compositions while they are kept at lower silica content. Addition of $\mathrm{SrO}$ at a given silica content decreases medium range order (e.g. smaller ring sizes than the one found for polymerized melts), in line with the presence of NBOs on aluminum units breaking the aluminosilicate network.

High amounts of high-coordinated aluminium are seen in per-aluminous compositions in the glasses and the melts. Competing mechanisms are at play during cooling, which are not observed along the joins $R=3$ and $R=1$, especially at low silica content. This could point towards the presence of tri-coordinated oxygen which would not be kept in significant amounts in the glasses.

On the modifier side, the strontium environment is seen to be more complex in the melt than in the glass, with a broader distribution of coordination number than that in the glass. We estimated it to be around 8 for the join $R=3$ and somewhat less for $R=1$, compared to values ranging between 8.5 and 9.0 obtained for the glassas shown byMD simulations (Charpentier et al., 2018; Novikov et al., 2017).

The evolution of the ${ }^{27} \mathrm{Al}$ NMR line position as a function of temperature and compositions shows that the distribution of $\mathrm{Al}-(\mathrm{OSi})_{\mathrm{p}}(\mathrm{OAl})_{(4-\mathrm{p})}$ units is the dominant parameter controlling the temperature dependence of the aluminum environment, a behavior related to increased fragility with increasing $\mathrm{Al} / \mathrm{Si}$ ratio as seen by Molecular Dynamic simulations (Scamehorn and Angell, 1991). We also probed the dynamics of those melts through the ${ }^{27} \mathrm{Al}$ NMR relaxation. This gives 
an "aluminum-centered" point of view that can be extended to the entire aluminosilicate network, in the limit that it is observed at temperature significantly higher than $T_{g}$. The correlation times derived by NMR and those obtained by fitting the shear viscosity at low and high temperature are in reasonably good agreement, showing that both mechanisms share at least some common features. The discrepancy lies in the activation energies, which are lower for NMR relaxation than for shear viscosity, showing that the temperature dependence of both processes at $T / T_{g} \geq 2$ is not strictly the same. Yet their correlation time being comparable one can convert the NMR ones in term of oxygen self-diffusion coefficient and show a decrease of oxygen diffusivity $D$ with increasing $\mathrm{Si} /(\mathrm{Al}+\mathrm{Si})$ ratio for polymerized melts along with an absence of compositional dependence for depolymerized ones.

Overall this study shows that if the structure of the strontium alumino-silicate glasses studied here are a good approximation of the structure of the high-temperature melts, some compositionaldependent discrepancies appear as well. Although technically challenging, a combined in-situ/exsitu study proves to be a very powerful approach to the description of the actual melt structure. This is even more true if one combines techniques providing information about the alumino-

silicate network and the cation environement, as ${ }^{27} \mathrm{Al}$ NMR and diffraction techniques do. For the high temperatures explored here ${ }^{27} \mathrm{Al}$ NMR turns out also to give insights into the oxygen selfdiffusion and its variation with composition, a parameter which is otherwise very difficult to obtain. Future plans are to develop an experimental approach which would allow us to perform NMR close to the glass transition, a very challenging task considering the lack of sensitivity of this technique.

\section{Acknowledgments}

We thank Alain Bertoni for help with the neutron diffraction experiments and the Institut LaueLangevin for the beamtime allocation. This research was conducted under funding from the ANR DyStrAS project (ANR-13-BS08-0012).

\section{References}

Abragam, A., 1961. The Principles of Nuclear Magnetism. Oxford University Press (Clarendon), London. 
Allwardt, J.R., Lee, S.K., Stebbins, J.F., 2003. Bonding preferences of non-bridging O atoms: Evidence from O-17 MAS and 3QMAS NMR on calcium aluminate and low-silica Caaluminosilicate glasses. American Mineralogist, 88(7): 949-954.

Angell, C.A., 1988. Perspective on the glass transition. Journal of Physics and Chemistry of Solids, 49(8): 863-871.

Benoit, M., Ispas, S., Tuckerman, M.E., 2001. Structural properties of molten silicates from ab initio molecular-dynamics simulations: Comparison between $\mathrm{CaO}-\mathrm{Al} 2 \mathrm{O} 3-\mathrm{SiO} 2$ and SiO2. Physical Review B, 64(22).

Capron, M. et al., 2001. Local structure and dynamics of high temperature SrO-Al2O3 liquids studied by Al-27 NMR and SrK-edge XAS spectroscopy. Journal of Non-Crystalline Solids, 293: 496-501.

Charpentier, T. et al., 2018. Structure of strontium aluminosilicate glasses from molecular dynamics simulations, neutron diffraction and nuclear magnetic resonance studies. The Journal of Physical Chemistry, in press.

Dingwell, D.B., Webb, S.L., 1990. Relaxation in silicate melts. European Journal of Mineralogy, 2(4): 427-449.

Dunn, T., 1982. Oxygen diffusion in three silicate melts along the join diopside-anorthite. Geochimica Et Cosmochimica Acta, 46(11): 2293-2299.

Farnan, I., Stebbins, J.F., 1990. High-temperature Si-29 NMR investigation of solid and molten silicates. Journal of the American Chemical Society, 112(1): 32-39.

Fischer, H.E. et al., 2002. D4c: A very high precision diffractometer for disordered materials. Applied Physics a-Materials Science \& Processing, 74: S160-S162.

Florian, P., Massiot, D., Poe, B., Farnan, I., Coutures, J.P., 1995. A time-resolved Al-27 NMRstudy of the cooling process of liquid alumina from $2450^{\circ} \mathrm{C}$ to crystallization. Solid State Nuclear Magnetic Resonance, 5(3): 233-238.

Florian, P., Sadiki, N., Massiot, D., Coutures, J.P., 2007. Al-27 NMR study of the structure of lanthanum- and yttrium-based aluminosilicate glasses and melts. Journal of Physical Chemistry B, 111(33): 9747-9757.

Florian, P., Veron, E., Green, T.F.G., Yates, J.R., Massiot, D., 2012. Elucidation of the A1/Si Ordering in Gehlenite Ca2Al2SiO7 by Combined 29Si and 27Al NMR Spectroscopy/Quantum Chemical Calculations. Chemistry of Materials, 24(21): 40684079.

George, A.M., Stebbins, J.F., 1996. Dynamics of Na in sodium aluminosilicate glasses and liquids. Physics and Chemistry of Minerals, 23(8): 526-534.

George, A.M., Stebbins, J.F., 1998. Structure and dynamics of magnesium in silicate melts: A high-temperature Mg-25 NMR study. American Mineralogist, 83(9-10): 1022-1029.

Greaves, G.N., Sen, S., 2007. Inorganic glasses, glass-forming liquids and amorphizing solids. Advances in Physics, 56(1): 1-166.

Gruener, G., Odier, P., Meneses, D.D., Florian, P., Richet, P., 2001. Bulk and local dynamics in glass-forming liquids: A viscosity, electrical conductivity, and NMR study of aluminosilicate melts. Physical Review B, 64(2).

Hennet, L. et al., 2014. Structural study of strontium aluminosilicate glasses and melts. Institut Laue-Langevin (ILL), doi:10.5291/ILL-DATA.6-03-432.

Hennet, L. et al., 2016. Neutron diffraction of calcium aluminosilicate glasses and melts. Journal of Non-Crystalline Solids, 451: 89-93. 
Hennet, L. et al., 2006. Levitation apparatus for neutron diffraction investigations on high temperature liquids. REVIEW OF SCIENTIFIC INSTRUMENTS, 77(5).

Howe, M.A., McGreevy, R.L., P., Z., 1996. CORRECT: a correction programme for neutron diffraction data. NFL Studsvik Internal Report

Jakse, N. et al., 2012. Interplay between non-bridging oxygen, triclusters, and fivefold Al coordination in low silica content calcium aluminosilicate melts. Applied Physics Letters, 101(20).

Jaworski, A., Stevensson, B., Eden, M., 2015. Direct 17O NMR experimental evidence for AlNBO bonds in Si-rich and highly polymerized aluminosilicate glasses. Physical Chemistry Chemical Physics, 17(28): 18269-18272.

Kanehashi, K., Stebbins, J.F., 2007. In situ high temperature Al-27 NMR study of structure and dynamics in a calcium aluminosilicate glass and melt. Journal of Non-Crystalline Solids, 353(44-46): 4001-4010.

Kargl, F., Meyer, A., 2004. Inelastic neutron scattering on sodium aluminosilicate melts: sodium diffusion and intermediate range order. Chemical Geology, 213(1-3): 165-172.

Krishnan, S., Weber, J.R.K., Ansell, S., Hixson, A.D., Nordine, P.C., 2000. Structure of liquid Al6Si2O13 (3 : 2 mullite). Journal of the American Ceramic Society, 83(11): 2777-2780.

Lacy, E.D., 1963. Aluminum in Glasses and Melts. Physics and Chemistry of Glasses, 4: 234238.

Le Caer, G., Brand, R.A., 1998. General models for the distributions of electric field gradients in disordered solids. Journal of Physics-Condensed Matter, 10(47): 10715-10774.

Le Losq, C. et al., 2017. Percolation channels: a universal idea to describe the atomic structure and dynamics of glasses and melts. Scientific Reports, 7(1): 16490.

Le Losq, C., Neuville, D.R., Florian, P., Henderson, G.S., Massiot, D., 2014. The role of Al3+ on rheology and structural changes in sodium silicate and aluminosilicate glasses and melts. Geochimica Et Cosmochimica Acta, 126(0): 495-517.

Liu, S.B., Pines, A., Brandriss, M., Stebbins, J.F., 1987. Relaxation Mechanisms and Effects of Motion in Albite (NaAlSi3O8) Liquid and Glass - A High-Temperature NMR-Study. Physics and Chemistry of Minerals, 15(2): 155-162.

Liu, S.B., Stebbins, J.F., Schneider, E., Pines, A., 1988. Diffusive motion in alkali silicate melts an NMR-study at high temperature. Geochimica Et Cosmochimica Acta, 52(2): 527-538.

Maekawa, H., Nakao, T., Shimokawa, S., Yokokawa, T., 1997. Coordination of sodium ions in $\mathrm{NaAlO}_{2}-\mathrm{SiO}_{2}$ melts: A high temperature Na-23 NMR study. Physics and Chemistry of Minerals, 24(1): 53-65.

Massiot, D. et al., 2008. Structure and dynamics of oxide melts and glasses: A view from multinuclear and high temperature NMR. Journal of Non-Crystalline Solids, 354(2-9): 249-254.

McMillan, P.F., Kirkpatrick, R.J., 1992. Al Coordination in Magneisum Aluminosilicate Glasses. American Mineralogist, 77(7-8): 898-900.

Nemausat, R. et al., 2015. Phonon effects on x-ray absorption and nuclear magnetic resonance spectroscopies. Physical Review B, 92(14).

Neuville, D.R. et al., 2008a. Environments around Al, Si, and Ca in aluminate and aluminosilicate melts by X-ray absorption spectroscopy at high temperature. American Mineralogist, 93(1): 228-234. 
Neuville, D.R., Cormier, L., Massiot, D., 2006. Al coordination and speciation in calcium aluminosilicate glasses: Effects of composition determined by Al-27 MQ-MAS NMR and Raman spectroscopy. Chemical Geology, 229(1-3): 173-185.

Neuville, D.R. et al., 2008b. Structure of Mg- and Mg/Ca aluminosilicate glasses: Al-27 NMR and Raman spectroscopy investigations. American Mineralogist, 93(11-12): 1721-1731.

Neuville, D.R., Henderson, G.S., Cormier, L., Massiot, D., 2010. The structure of crystals, glasses, and melts along the $\mathrm{CaO}-\mathrm{Al} 2 \mathrm{O} 3$ join: Results from Raman, $\mathrm{Al} \mathrm{L}$ - and $\mathrm{K}$-edge $\mathrm{X}$ ray absorption, and Al-27 NMR spectroscopy. American Mineralogist, 95(10): 15801589.

Neuville, D.R., Hennet, L., Florian, P., de Ligny, D., 2014. In situ High-Temperature Experiments. In: Henderson, G.S., Neuville, D.R., Downs, R.T. (Eds.), Spectroscopic Methods in Mineralology and Materials Sciences. Reviews in Mineralogy \& Geochemistry. Mineralogical Soc Amer, Chantilly, pp. 779-800.

Neuville, D.R., Mysen, B.O., 1996. Role of aluminium in the silicate network: In situ, hightemperature study of glasses and melts on the join $\mathrm{SiO} 2-\mathrm{NaAlO} 2$. Geochimica Et Cosmochimica Acta, 60(10): 1727-1737.

Ni, H.W., Hui, H.J., Steinle-Neumann, G., 2015. Transport properties of silicate melts. Reviews of Geophysics, 53(3): 715-744.

Novikov, A.N. et al., 2017. Al and Sr environment in tectosilicate glasses and melts: Viscosity, Raman and NMR investigation. Chemical Geology, 461: 115-127.

Perkins, W.G., Begeal, D.R., 1971. Diffusion and Permeation of He, Ne, Ar, Kr, and D2 through Silicon Oxide Thin Films. The Journal of Chemical Physics, 54(4): 1683-1694.

Petit, D., Korb, J.P., 1988. Fictitious Spin-1/2 Operators and Multitransition Nuclear-Relaxation in Solids - General Theory. Physical Review B, 37(10): 5761-5780.

Poe, B.T., McMillan, P.F., Cote, B., Massiot, D., Coutures, J.P., 1992. SiO2-A12O3 Liquids: InSitu Study and High-Temperature Al-27 NMR-Spectroscopy and Molecular-Dynamics Simulation. Journal of Physical Chemistry, 96(21): 8220-8224.

Scamehorn, C.A., Angell, C.A., 1991. Viscosity-Temperature Relations and Structure in Fully Polymerized Aluminosilicate Melts from Ion Dynamics Simulations. Geochimica Et Cosmochimica Acta, 55(3): 721-730.

Stebbins, J.F., 2016. Glass structure, melt structure, and dynamics: Some concepts for petrology. American Mineralogist, 101(3-4): 753-768.

Stebbins, J.F., Dubinsky, E.V., Kanehashi, K., Kelsey, K.E., 2008. Temperature effects on nonbridging oxygen and aluminum coordination number in calcium aluminosilicate glasses and melts. Geochimica Et Cosmochimica Acta, 72(3): 910-925.

Stebbins, J.F., Murdoch, J.B., Schneider, E., Carmichael, I.S.E., Pines, A., 1985. A HighTemperature High-Resolution NMR-Study of Na-23, Al-27 and Si-29 in Molten Silicates. Nature, 314(6008): 250-252.

Stebbins, J.F., Wu, J., Thompson, L.M., 2013. Interactions between network cation coordination and non-bridging oxygen abundance in oxide glasses and melts: Insights from NMR spectroscopy. Chemical Geology, 346(0): 34-46.

Stebbins, J.F., Xu, Z., 1997. NMR evidence for excess non-bridging oxygen in an aluminosilicate glass. Nature, 390(6655): 60-62.

Toplis, M.J., Dingwell, D.B., 2004. Shear viscosities of CaO-AL(2)O(3)-SiO2, and MgOA12O3-SiO2 liquids: Implications for the structural role of aluminium and the degree of 
polymerisation of synthetic and natural aluminosilicate melts. Geochimica Et Cosmochimica Acta, 68(24): 5169-5188.

Toplis, M.J., Dingwell, D.B., Lenci, T., 1997. Peraluminous viscosity maxima in Na2O-Al2O3$\mathrm{SiO} 2$ liquids: The role of triclusters in tectosilicate melts. Geochimica Et Cosmochimica Acta, 61(13): 2605-2612.

Urbain, G., Bottinga, Y., Richet, P., 1982. Viscosity of Liquid Silica, Silicates and AluminoSilicates. Geochimica Et Cosmochimica Acta, 46(6): 1061-1072.

Vargheese, K.D., Tandia, A., Mauro, J.C., 2010. Origin of dynamical heterogeneities in calcium aluminosilicate liquids. Journal of Chemical Physics, 132(19).

Wert, C.A., 1950. Diffusion Coefficient of C in \$lensuremath \{lalpha\} \$-Iron. Physical Review, 79(4): 601-605.

Wolfram Research, I., 2015. Mathematica. Wolfram Research, Inc., Champaign, Illinois.

Zener, C., 1951. Theory of Do for Atomic Diffusion in Metals. Journal of Applied Physics, 22(4): 372-375. 